\title{
Circumglobal Response to Prescribed Soil Moisture over North America
}

\author{
Haiyan Teng, Grant Branstator, Ahmed B. TAwfik, And Patrick Callaghan \\ National Center for Atmospheric Research, Boulder, Colorado
}

(Manuscript received 2 December 2018, in final form 1 February 2019)

\begin{abstract}
A series of idealized prescribed soil moisture experiments is performed with the atmosphere/land standalone configuration of the Community Earth System Model, version 1, in an effort to find sources of predictability for high-impact stationary wave anomalies observed in recent boreal summers. We arbitrarily prescribe soil water to have a zero value at selected domains in the continental United States and run 100member ensembles to examine the monthly and seasonal mean response. Contrary to the lack of a substantial response in the boreal winter, the summertime circulation response is robust, consistent, and circumglobal. While the stationary wave response over the North America and North Atlantic sectors can be well explained by the reaction of a linear dynamical system to heating anomalies caused by the imposed dry land surface, nonlinear processes involving synoptic eddies play a crucial role in forming the remote response in Eurasia and the North Pacific Ocean. A number of other possible factors contributing to the circulation responses are also discussed. Overall, the experiments suggest that, in the boreal summer, soil moisture may contribute to the predictability of high-impact stationary wave events, which can impact regions that are great distances from these source regions.
\end{abstract}

\section{Introduction}

Despite tremendous progress in the past several decades in understanding how tropical sea surface temperature (SST) can provide extended predictability to the midlatitude atmospheric circulation (e.g., Trenberth et al. 1988), many extreme events in the midlatitudes are associated with stationary wave anomalies that do not necessarily originate from tropical forcing (Trenberth et al. 1998). Besides SST anomalies, land conditions such as soil moisture can also contribute to low-frequency atmospheric variability and predictability (e.g., Douville and Chauvin 2000; Dirmeyer 2005; Conil et al. 2007). In this study, we use prescribed soil moisture experiments with the Community Earth System Model, version1 (CESM1; Hurrell et al. 2013) to demonstrate and explain how regional land forcing can produce widespread, indeed circumglobal, teleconnection responses in the boreal summer.

As reported in several comprehensive review papers (Seneviratne et al. 2010; Koster et al. 2017; Miralles et al. 2018), the interaction between soil moisture and air temperature through modulation of surface sensible heat flux is a straightforward process that can impact

\footnotetext{
Corresponding author: Haiyan Teng, hteng@ucar.edu
}

local atmospheric conditions. The more complicated feedback between soil moisture and precipitation (Findell and Eltahir 2003; Ek and Holtslag 2004; Gentine et al. 2013; Guillod et al. 2015; Tawfik et al. 2015 ) is another land-atmosphere interaction that can influence local conditions. Since studies on landatmosphere coupling have traditionally focused on these now widely recognized local feedbacks, what may be more controversial to acknowledge is that anomalous land conditions such as drought at one location have the potential, by producing local anomalous atmospheric heat sources, to excite quasi-stationary Rossby wave anomalies, and hence remote impacts (e.g., Douville and Chauvin 2000; Douville 2002; Koster et al. 2016; Wang et al. 2017). More frequent and amplified stationary wave anomalies have been observed in the recent decades (Screen and Simmonds 2014; Horton et al. 2015; Hoskins and Woollings 2015), and some are associated with multiple extreme events (heat waves, wild fires, floods, droughts) at different locations, such as the 2010 Russian heat wave and Pakistan flood (Trenberth and Fasullo 2012). Many of these events do not exhibit a clear tropical forcing, raising the question of whether land conditions can contribute to the cause and predictability of these events. 
Soil moisture may play a more prominent role in climate variability in the future warmer climate (Dirmeyer et al. 2012; Douville et al. 2016; Teng et al. 2016). Taking the climate change projection by the CESM1 large ensemble experiment (Kay et al. 2015) as an example, in addition to a shift in mean temperatures, anthropogenic forcing could enhance the future subseasonal temperature variability by approximately $20 \%$ in the U.S. Great Plains in the summers of 2070 2100 relative to 1980-2010 (Teng et al. 2016), possibly due to enhanced land-atmosphere interaction under the future warmer climate (Schär et al. 2004; Seneviratne et al. 2010; Fischer et al. 2007, 2012). However, in order to establish a more rigorous causeand-effect relationship than was established in that study, additional experiments dedicated to process understanding are needed. One approach is to employ idealized prescribed soil moisture experiments, which is the approach used in the current paper, to study how local land conditions can impact the atmospheric state.

As far as we are aware, systematic investigation of soil moisture's impact on circulation has not been done with CESM1 prior to our study, although there have been some pioneering efforts with other general circulation models (GCMs). We want to especially acknowledge Koster et al. (2016), who showed how a rainfall deficit in the continental United States can affect the summer circulation in North America and the North Atlantic Ocean. Perhaps one of their most interesting findings is that regardless of the specific location of the dryness within the United States, the atmospheric circulation tends to respond in a consistent way. While there are merits in simply testing this finding with a different GCM, more importantly we demonstrate below that if one examines response at locations beyond the North America/North Atlantic sector studied by Koster et al. (2016), regional land forcing can produce circumglobal teleconnection responses. Thus, our experiments can be regarded not only as sensitivity tests of atmosphere-land coupling and resulting regional influences in CESM1, but also as testbeds for forcing mechanisms that can impact an entire hemisphere.

The term "circumglobal teleconnection" (CGT) was introduced by Branstator (2002) to refer to wintertime stationary wave covariability trapped in the vicinity of the upper-troposphere mean jet streams, due to the waveguide effect of the meridional gradients in absolute vorticity (Hoskins and Ambrizzi 1993; Branstator 1992). Generally speaking, waveguide-induced teleconnections are much weaker and less circumglobal in the summer, with the subseasonal covarability more confined to two separate sectors of the globe where the jets are strong (Branstator and Teng 2017). However,
CGTs do appear to contribute to various summertime observed phenomena (Ding and Wang 2005; Yasui and Watanabe 2010; Teng et al. 2013). Most noteworthy are their connections with some high-impact extreme events (Screen and Simmonds 2014; Petoukhov et al. 2013; Fragkoulidis et al. 2018) and the appearance of an upward trend in frequency of occurrence of a zonal wavenumber-5 CGT pattern since the 1990s (Lee et al. 2017). While it remains controversial whether external forcing is crucial for the summertime CGTs (Yasui and Watanabe 2010), another question that is also highly relevant to extreme events and to which our results pertain is this: What forcing can easily excite the CGTs and is such forcing predictable?

This paper is organized as follows. After introducing the models and experiments in section 2, we present an overview of seasonal and monthly mean circulation responses to prescribed soil moisture in section 3. In section 4 , we conduct a suite of experiments to test the sensitivity of the circulation response to a number of factors in the experimental design. In section 5, we focus on an experiment in which soil moisture is prescribed in only the Great Plains and investigate the mechanisms of the resulting summertime circumglobal stationary wave response, followed by a summary and discussion in section 6 .

\section{Models and experiments}

\section{a. CESM1 prescribed soil moisture experiments}

The prescribed soil moisture experiments in our study are performed with the atmosphere/land stand-alone configuration (often referred to as CAM5) of CESM1, an Earth system model consisting of fully coupled atmosphere, ocean, land, and sea ice components. We use the version of CAM5 that has 30 vertical levels and a horizontal resolution of roughly $1^{\circ}$. For all the CAM5 simulations conducted here, SST and sea ice concentrations are prescribed by the monthly mean climatologies derived from the CESM1 fully coupled preindustrial control run for years 402-1510. The CAM5 control run, which was run for 2600 years, is part of the CESM1 large ensemble project (Kay et al. 2015). While more details of the model and the experiments are documented in Hurrell et al. (2013) and Kay et al. (2015), Branstator and Teng (2017) have compared the waveguide teleconnections in the model with the observations.

For perturbed experiments, at each time step soil water is set to a prescribed value within a selected domain, while outside of that domain atmosphere and land are run in the same fully coupled manner as in the 


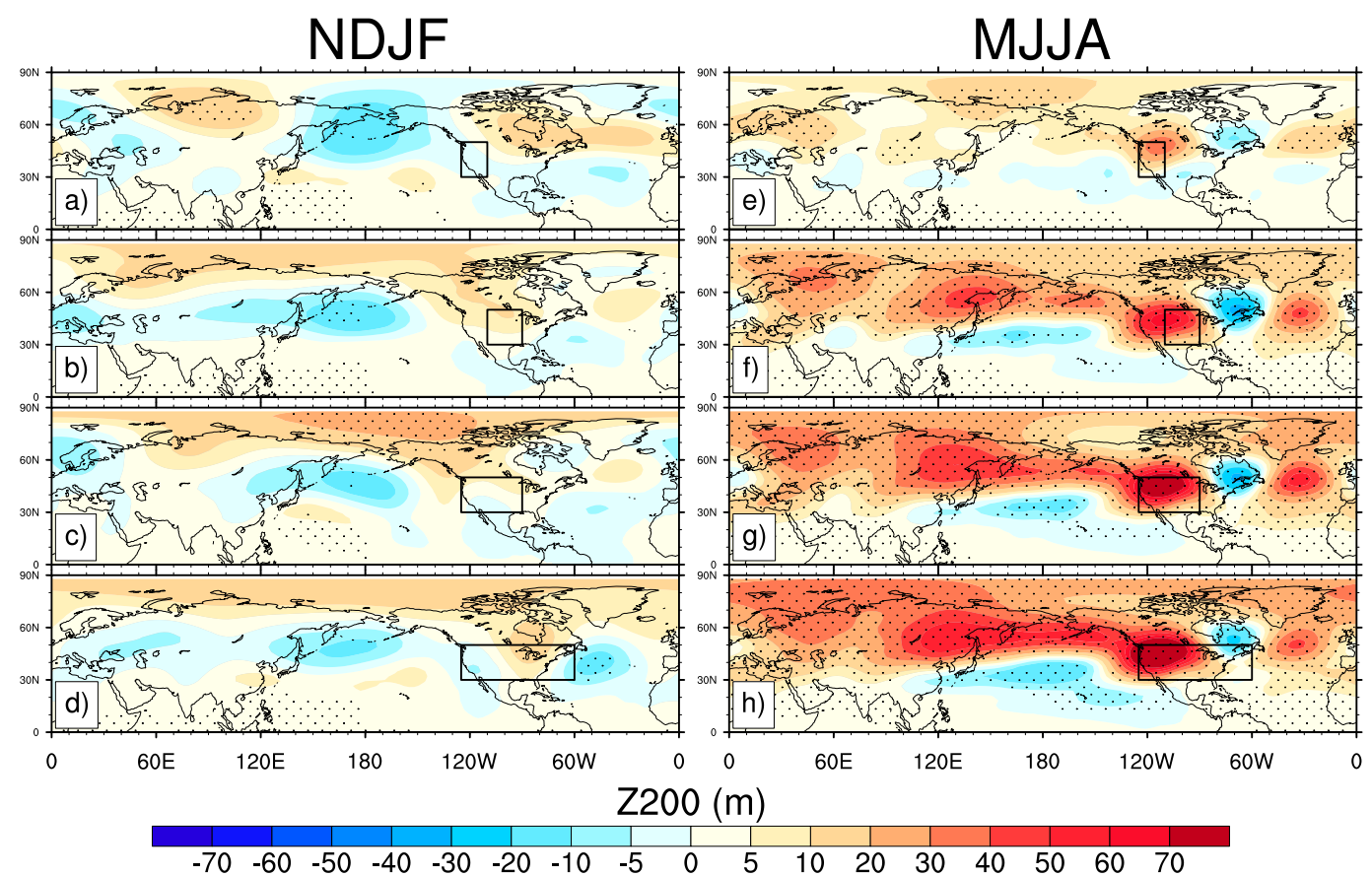

FIG. 1. Seasonal mean 200-hPa geopotential height (Z200) response to soil water depletion at four different domains indicated by the black box in (a)-(d) November-February and (e)-(h) May-August. Stippling represents the $95 \%$ confidence level with a Student's $t$ test.

control run. For each experiment, we run 100 perturbed members, which differ only in the initial conditions, and those initial conditions are taken from the last 500 years of the CAM5 control run and are at least five years apart. All results presented below are derived from these 100-member ensembles. For most cases, we integrate the perturbed experiments for four months, and then compare the output with those in the control run with the same model dates.

\section{b. A linear stationary wave model}

CESM1 may be good for simulating variability and the forced response of the climate system, but in order to understand such behavior, simple models are often needed. Here, we turn to the same linear stationary wave model (Branstator 1990) that we have frequently used in our previous studies (Branstator and Teng 2017; Teng et al. 2016) to help interpret the stationary wave response produced by CAM5 as it reacts to the prescribed soil moisture anomalies.

The model is a much simpler dynamical system than CAM5 and consists of the discretized sigma coordinate primitive equations as they were represented in a much earlier version of CAM5. The atmospheric states, which consist of relative vorticity, divergence, air temperature, and surface pressure, are divided into a climatological mean basic state and perturbations, which are represented in terms of spherical harmonic coefficients. The model perturbations are forced by imposed sources of temperature, divergence, or vorticity. We only consider steady sources. After linearization, the steady primitive equations can expressed as $\mathbf{L X}=\mathbf{R}$, where $\mathbf{X}$ contains the coefficients of all perturbation fields at all levels, $\mathbf{L}$ is a real matrix where the climatological mean states are embedded, and $\mathbf{R}$ contains the coefficients of the forcing. Hence, the solutions of stationary wave anomalies in $\mathbf{X}$ are found through direct solution of the steady equation rather than through time integrations.

We have run the linear stationary wave model with a horizontal truncation of R15 at 10 equally spaced vertical levels $(\sigma=0.05, \ldots, 0.95)$. The mean states are MayAugust climatological values from the CAM5 control run. (Our results are not affected in any important way when we substitute a reanalysis climatology.) The linear model includes damping coefficients for each state variable, which are set to $(2 \text { days })^{-1}$ in the bottom two levels, and $(7 \text { days })^{-1}$ for the rest of the levels. More details of the model are available in the appendix of Branstator (1990).

\section{Seasonal and monthly mean response}

We start with four different domains indicated by the black box in Figs. 1a-d, including the western United States (Fig. 1a), the Great Plains (Fig. 1b), the western 

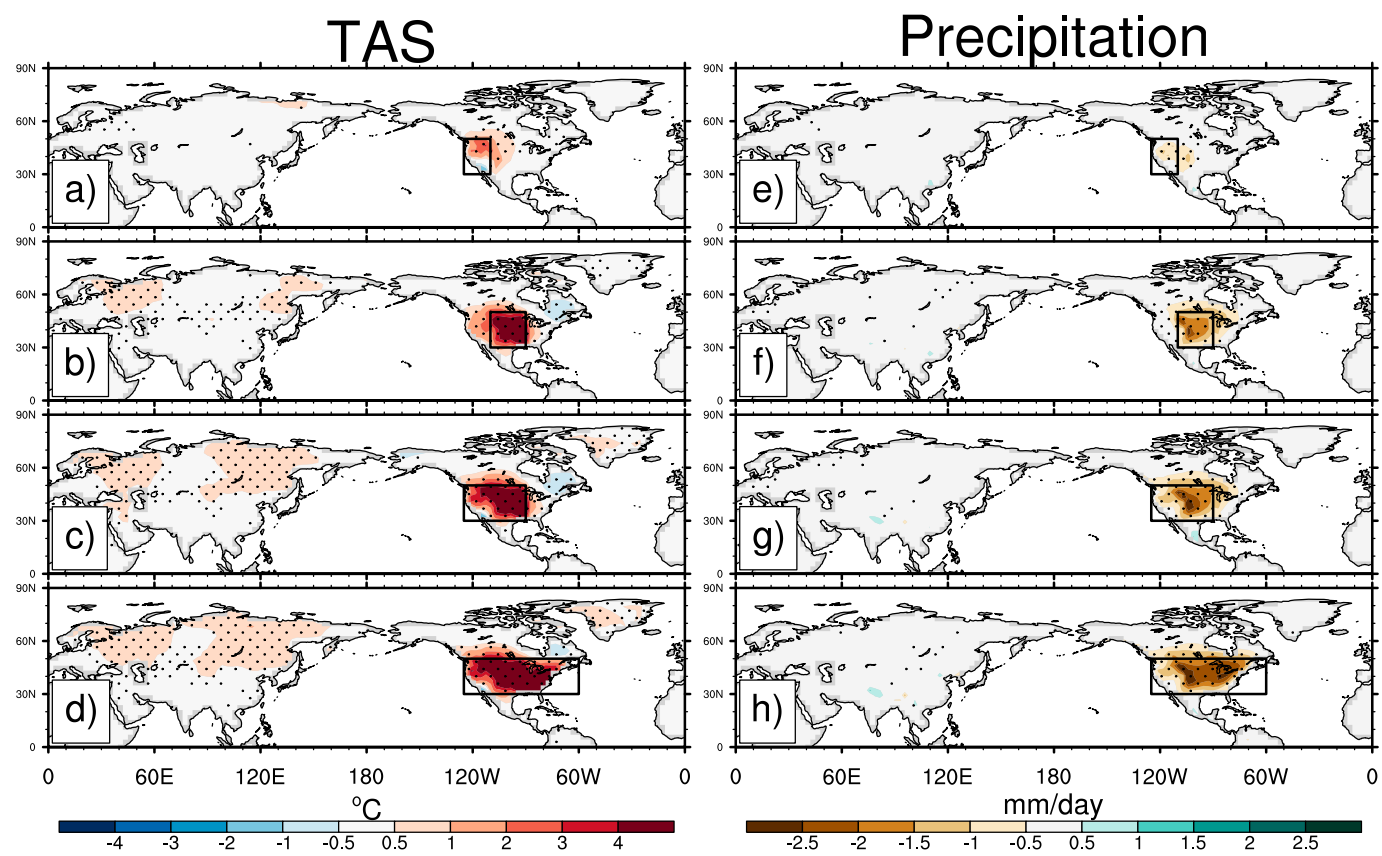

FIG. 2. As in Fig. 1, but for surface air temperature and precipitation response in the four summertime soil water depletion experiments during May-August.

and central United States (Fig. 1c), and the entire continental United States (Fig. 1d). Within a given box we set soil water to zero at each time step to mimic drought conditions, while, as mentioned, outside the box land is fully coupled with the atmosphere as in the control run. For each case, we run ensemble members starting from the first day of November (Fig. 1, left) and May (Fig. 1, right), respectively, for four months.

Figure 1 shows the response of seasonal mean 200-hPa geopotential height (Z200) anomalies when soil water is removed in each of the four domains. In contrast to a weak response in the winter (Figs. 1a-d), three out of the four cases show substantial globe-wide circulation responses in the summer (Figs. 1f-h). In fact, almost the entire midlatitude region between $50^{\circ}$ and $70^{\circ} \mathrm{N}$ is dominated by a wave train comprised of high pressure ridges in the western-central North America, the North Atlantic, northern Europe and the Barents Sea, and the Far East and Sea of Okhotsk, and a low pressure trough over Newfoundland. Despite variations in the location of the soil moisture forcing, the placement of the ridges and trough is quite consistent (Figs. 1f-h).

Based on these solutions we decide to focus on the summer experiments for the rest of the paper. The summertime seasonal mean responses in surface air temperature (TAS) and precipitation for the four domains are plotted in Fig. 2. Within the boxes, the warming can be larger than $4^{\circ} \mathrm{C}$ (Figs. 2b-d), large enough to produce a heat wave. Over Eurasia, there are two distinct regions, northern Europe and the Far East, where the TAS anomalies exceed $0.5^{\circ} \mathrm{C}$. Such warming, both locally and remotely, can make soil moisture a likely contributor to uncertainty in climate sensitivity (Douville et al. 2016) given likely shortcomings in the treatment of pertinent processes. Associated with the surface drying and warming, the seasonal mean precipitation within the boxes is reduced by $1-3 \mathrm{~mm}_{\text {day }}{ }^{-1}$, corresponding to roughly $50 \%-60 \%$ of the climatology in the control run, consistent with a positive feedback between soil moisture and precipitation.

Based on simple linear wave propagation theory (Hoskins et al. 1977), there is the possibility that the circulation response may vary during the summer in concert with the changing climatological mean states. In Fig. 3 we investigate this possibility by examining a different set of experiments, each of which begins on the first day of a different summer month. Specifically, we compare the ensemble mean Z200 response when soil water is removed in the Great Plains box starting from the first day of May (Fig. 3a), June (Fig. 3b), July (Fig. 3c), and August (Fig. 3d). The Z200 responses in the first month of the forcing (Fig. 3) all show a distinct circumglobal wave train, indicating that the hemispheric-wide patterns in Fig. 1 are generated within one month. The pattern of the Z200 anomalies is quite similar in North America and the North Atlantic sector, all characterized by positive anomalies in the west-central part of North America, negative 


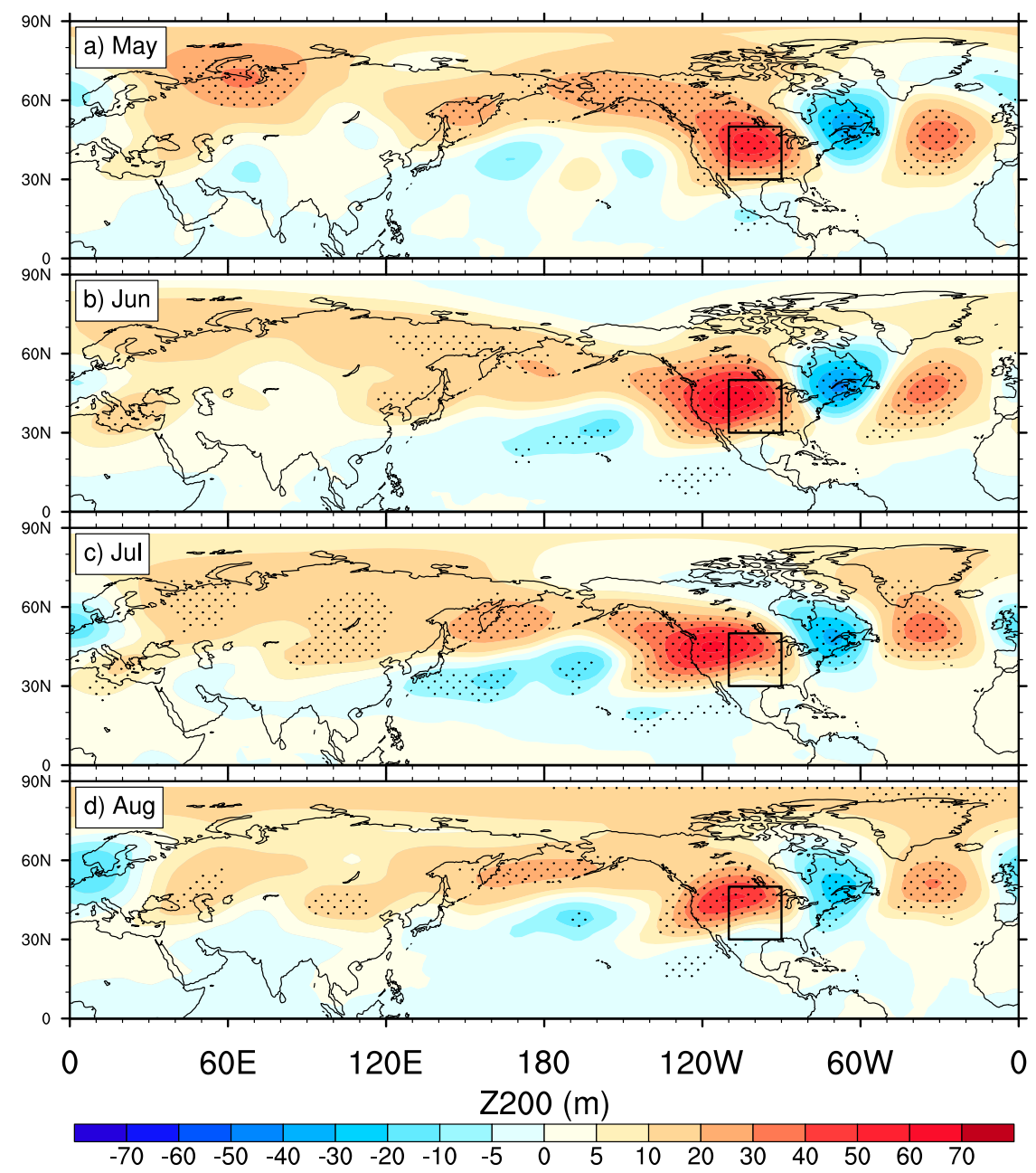

FIG. 3. Monthly averaged Z200 response in (a) May, (b) June, (c) July, and (d) August, when soil water is depleted in the Great Plains box, from the first to the last day of each indicated month. Stippling represents the $95 \%$ confidence level with a Student's $t$ test.

anomalies to the northeast, and positive anomalies to the south of Greenland. The month-to-month variations in the circulation response are more evident over Eurasia. In contrast to May when the wave train is dominated by positive anomalies in regions surrounding the Kara Sea, the center of positive anomalies shifts to north of Caspian Sea in August. It is also noteworthy that the response in both July and August resembles a CGT pattern that is associated with interannual variability of the Indian summer monsoon (Ding and Wang 2005) and that has exhibited an upward trend in occurrence in the recent decades (Lee et al. 2017).

\section{Sensitivity tests}

Next we carry out a series of sensitivity tests to determine how robust our findings are to a number of factors, concerning the location, depth, persistence, and strength of the soil moisture forcing.

\section{a. Twenty-one subdomains in the United States}

Since droughts often occur on regional scales, it is useful to reduce the size of the geographical domain for the imposed dryness and check whether our finding remains valid. To facilitate comparison with a previous study (Koster et al. 2016), we divide the continental United States into the same 21 subdomains (Fig. 4; see Koster et al. 2016, their Fig. 2), each roughly $7^{\circ}$ latitude $\times 7^{\circ}$ longitude. For each subdomain, we set soil water to close to 0 and run a 100-member experiment with each member beginning on 1 May and lasting until the end of August.

Each panel in Fig. 5 shows the May-August averaged Z200 response to soil water depletion for one of the 21 subdomains, with the panel label corresponding to the 


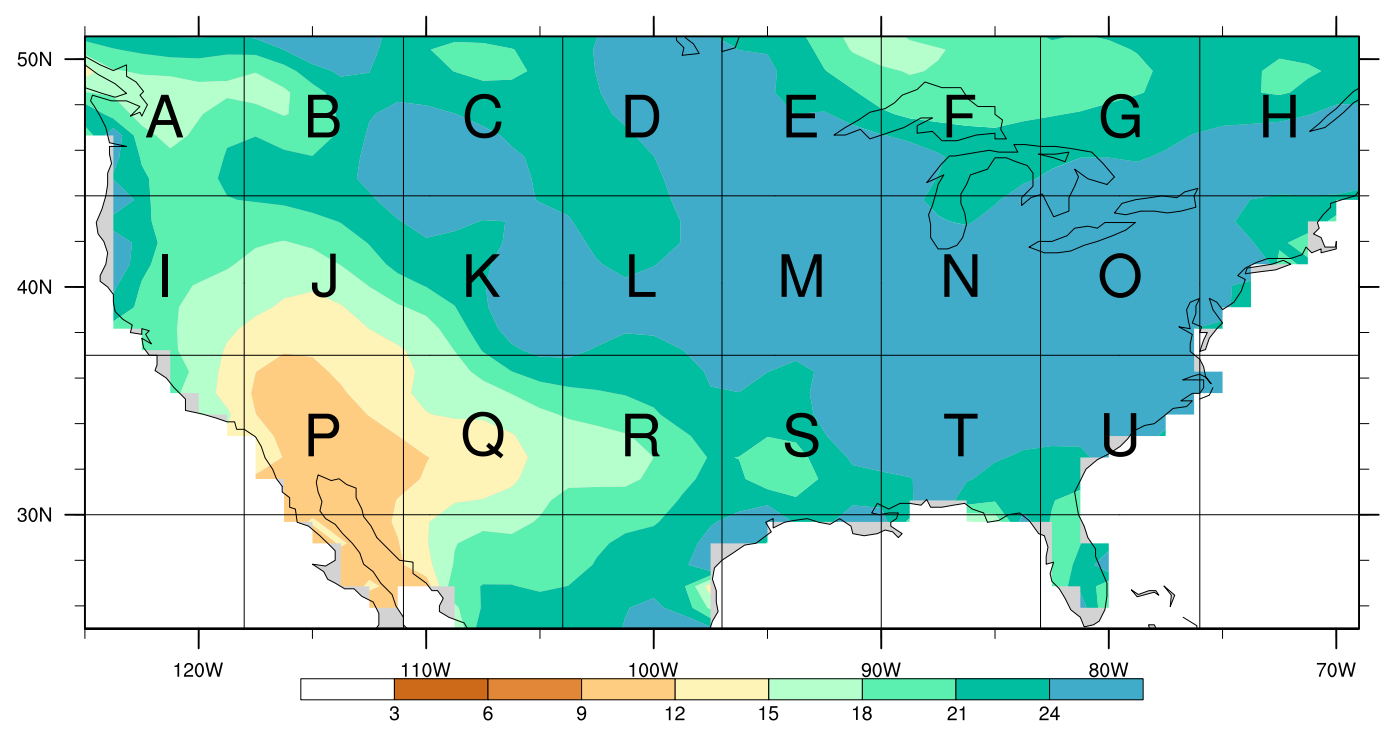

FIG. 4. Twenty-one subdomains of soil water depletion experiments in May-August [the domains were adopted from Koster et al. (2016)]. Shading represents the top 10-cm soil water climatology $\left(\mathrm{kg} \mathrm{m}^{-2}\right)$ during May-August in the CESM1 preindustrial control run.

index of the subdomains (Fig. 4). Note that the scaling in Fig. 5 is different from that in Figs. 1 and 3. As expected, the amplitude of the Z200 anomalies weaken when the size of the forcing domain is reduced from the earlier experiments (Figs. 1 and 3). Subdomains A, G, H, O, P, and $\mathrm{Q}$ have the least total area of significant response at $30^{\circ}-70^{\circ} \mathrm{N}$. In contrast, the seven subdomains that can force the strongest root-mean-square averaged response in the same midlatitude belt are $\mathrm{K}, \mathrm{L}, \mathrm{M}, \mathrm{N}, \mathrm{R}, \mathrm{S}$, and T, which are located along a swath extending from northcentral North America to the Gulf of Mexico, and many of them are within the Great Plains box defined in Fig. 1 . One may expect greater response from subdomains with higher climatological soil moisture (shading in Fig. 4) as, by design, setting soil moisture to zero will correspond to stronger soil water depletion. Instead, it is the semiarid areas that produce the stronger circulation responses.

In contrast to the apparent variations in the amplitude of the Z200 anomalies, the locations of the ridges and troughs are rather fixed longitudinally. In general, the ridges tend to be centered at $40^{\circ} \mathrm{E}, 140^{\circ} \mathrm{E}, 110^{\circ} \mathrm{W}$, and $30^{\circ} \mathrm{W}$, compared to troughs at $90^{\circ} \mathrm{E}, 180^{\circ}$, and $60^{\circ} \mathrm{W}$. Wang et al. (2019) attributed the phase-locking of the circulation response in Koster et al. (2016) to local orography. Another interesting feature is that not every subdomain forces positive anomalies in the westerncentral United States. Those that do (subdomains B, C, $\mathrm{D}, \mathrm{K}, \mathrm{L}, \mathrm{M}, \mathrm{R}, \mathrm{S}$, and $\mathrm{T}$ ) tend to be at or adjacent to the Great Plains box. The same group of subdomains also seems to produce stronger responses throughout the entire midlatitudes.
Although Koster et al. (2016) mainly focused on the response in the North America/North Atlantic sector, our results support their finding that perturbations in the Great Plains soil moisture can more effectively trigger circulation responses compared to other U.S. subdomains. In a way, this result supports the notion that the Great Plains is one of the regions with the strongest atmosphere-land interaction (Koster et al. 2004; Seneviratne et al. 2010). In a separate effort when we compared waveguide teleconnections in observations, CAM5, and the linear planetary wave model, we found in all three dynamical systems that the Great Plains is consistently associated with the strongest waveguide teleconnections in boreal summer (Branstator and Teng 2017). However, atmosphere-land interaction is not represented in the linear model, which indicates that certain attributes in the climatological mean states in the atmosphere, such as the effect of the orographic lifting (Wang et al. 2019), can also facilitate forcing in the Great Plains to excite remote responses.

\section{b. Depth}

For all the experiments shown above, we prescribe soil water in the entire column to zero when we impose the dryness. One may wonder whether such a crude approach can induce unrealistic shocks to the regional hydrological cycle and ecosystem. Since soil moisture mainly affects the atmosphere through the surface flux, we speculate that removal of soil water at close to the surface layer is enough to induce circulation responses similar to those found in the earlier experiments (Figs. 1f, 3). 


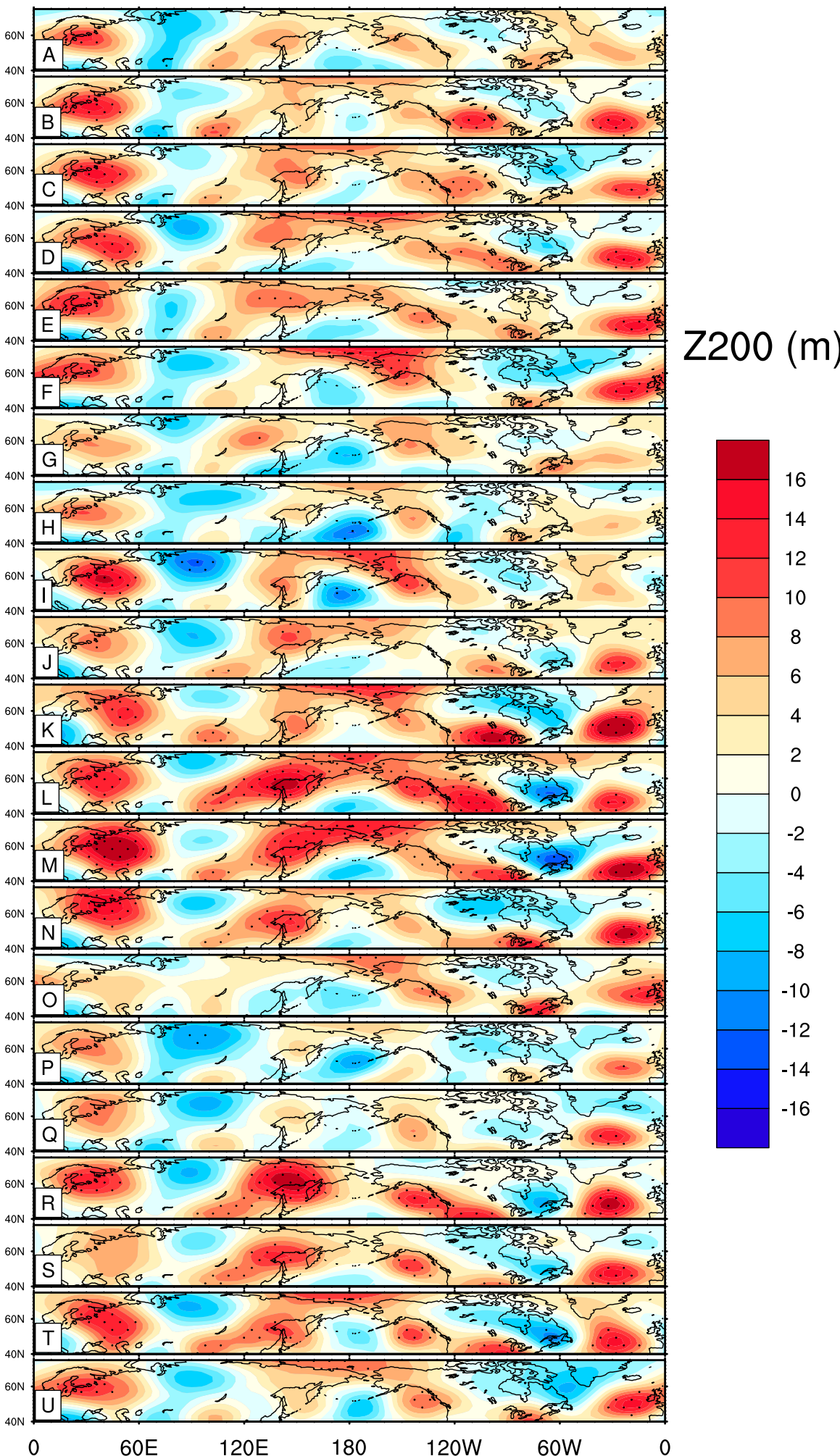

FIG. 5. (a)-(u) Seasonal mean $\mathrm{Z} 200$ response at $45^{\circ}-80^{\circ} \mathrm{N}$ when soil water in each of the 21 subdomains is depleted in May-August, with the panel label corresponding to the index for the subdomains (Fig. 4). Stippling represents the 95\% confidence level with a Student's $t$ test. 

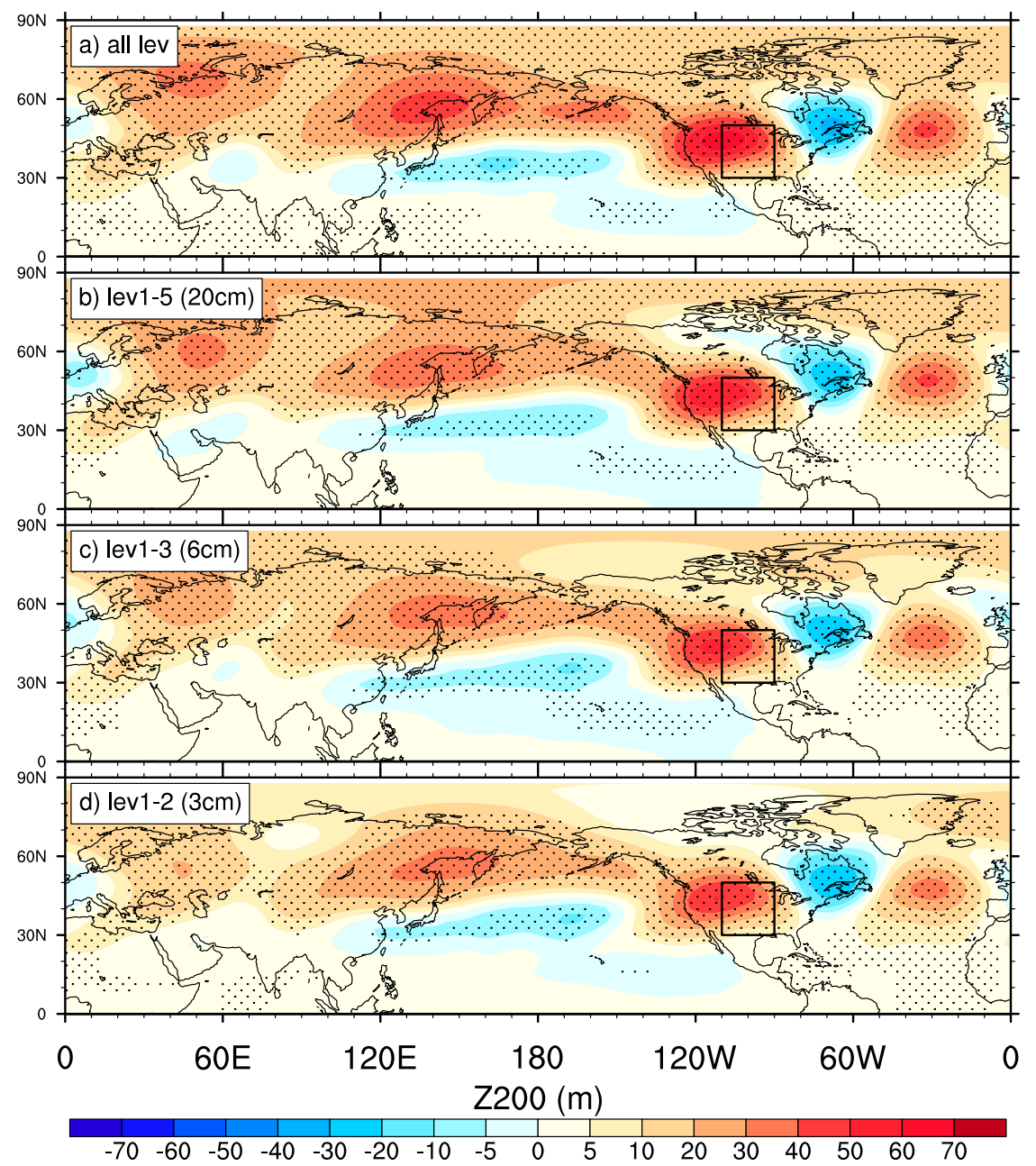

FIG. 6. Seasonal mean Z200 response when soil water is depleted at (a) all layers, (b) the top five layers $(43 \mathrm{~cm}),(\mathrm{c})$ the top three layers $(10 \mathrm{~cm})$, and $(\mathrm{d})$ the top two layers $(3.5 \mathrm{~cm})$ in the Great Plains during May-August. Stippling represents the $95 \%$ confidence level with a Student's $t$ test.

To test this speculation, we carry out three sets of experiments using the same setup employed in the earlier May-August Great Plains experiment (Fig. 1f), except that at each time step soil water is set to zero at the top five layers $(\sim 43 \mathrm{~cm})$, three layers $(\sim 10 \mathrm{~cm})$, and two layers $(\sim 3.5 \mathrm{~cm})$, respectively. The May-August ensemble averaged Z200 responses from these new experiments are compared with that from the allcolumn experiment (Fig. 6). While the spatial pattern of the Z200 responses look very similar to each other and to the all-column experiment, the amplitude slightly decreases as we reduce the soil water depletion layers. A measure of this weakening is that the rootmean-square of the $\mathrm{Z} 200$ anomalies at $40^{\circ}-70^{\circ} \mathrm{N}$ is reduced by roughly $10 \%, 21 \%$, and $25 \%$, respectively, when soil water is depleted only at the top five (Fig. 6b), three (Fig. 6c), and two (Fig. 6d) layers relative to the all-column experiment (Fig. 6a).

\section{c. Short-lived forcing}

All the circumglobal circulation responses presented so far are produced by steady soil moisture forcing; soil moisture within the selected domain is set to close to zero at each time step throughout the experiment. In nature, even during severe droughts, dry spells can be interrupted by some precipitation events, raising the question of whether a short period of drought can induce a long lasting response through various processes that can produce memory in the coupled system. This motivates us to carry out some multimonth experiments in which regional soil water is set to zero only for the first month and then followed by months during which the 

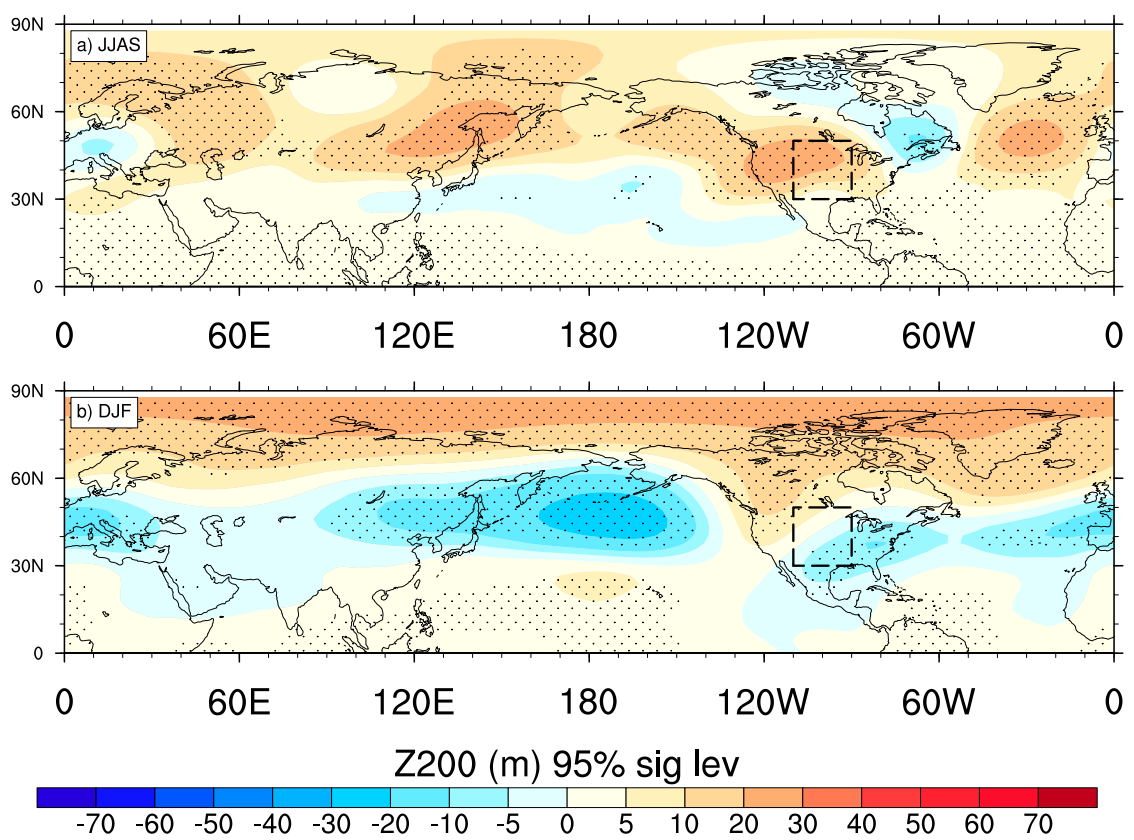

FIG. 7. Lagged Z200 response in (a) June-September and (b) December-February from the short-lived forcing experiments, in which soil water is depleted in the top two layers $(3.5 \mathrm{~cm})$ in the Great Plains for only a month, starting from the first day of May, June, and July, respectively, followed by free running through the end of the following winter. Stippling represents the $95 \%$ confidence level with a Student's $t$ test.

soil moisture is treated exactly as it is in the control run. Note that this means that the responses in the runs that we present below result from control integrations with special land/atmosphere initial conditions, namely conditions produced by one month of dry land.

To increase the sample size, we start four sets of experiments, each consisting of 100 members, on the first day of May, June, July, and August, with soil water set to zero in the top two layers $(\sim 3.5 \mathrm{~cm})$ within the Great Plains box (indicated by the dashed line in Fig. 7). After one month of integration, we take the conditions on the first day of June, July, August, and September, respectively, and continue the integrations until the end of February of the following winter with the model set to its control run configuration.

We then take the June-September, July-September, August-September, and September monthly Z200 outputs, from these four sets of experiments respectively, and compare their mean values with means calculated from the standard control run data in the same months and years (Fig. 7a). Even without any imposed forcing, there is a robust circulation response in the new runs during the remaining summer. Despite the weaker amplitude, the wave pattern resembles the response pattern in the steady forcing case (Fig. 6d).

The summertime soil water short-lived forcing also appears to impact the atmospheric circulation in the following winter. In Fig. 7b, we show the DJF Z200 anomalies averaged from the four sets of short-lived forcing experiments. While low pressure anomalies prevail in several midlatitude areas including the northern Pacific Ocean, the southeastern coast of the United States, and the Mediterranean, the entire Arctic Ocean is dominated by high pressure anomalies. These findings suggest that the summer soil moisture in the Great Plains can potentially provide predictability to the atmospheric circulation in the following winter in CESM1. Keep in mind that we are unable to detect any robust circulation response when we deplete soil water in the Great Plains in the winter season (Fig. 1b); therefore, other factors (e.g., snow and ice at higher latitudes) must play a role in order to pass the information in the summer soil moisture to the winter circulation. This issue will require further study.

\section{d. Strength of forcing}

In all experiments we have presented above, we simply set soil water within a selected domain to zero, which is a condition that falls outside the model's natural trajectory. Taking the Great Plains box as an example, the May-August climatology mean and interannual standard deviation of the domain averaged soil liquid water is $3.5 \pm 0.17$ and $6.0 \pm 0.24 \mathrm{~kg} \mathrm{~m}^{-2}$, in the top two layers (at 0.7 and $2.8 \mathrm{~cm}$ ), respectively in the CAM5 control 
run. In other words, even during the most severe droughts in the model, the top layer soil water is never close to zero. Although applying a strong forcing is often a quick way to get robust reactions of a dynamic system, it is also important to explore a broad range of forcing strength to learn about the model's sensitivity.

Again, we only prescribe soil water in the top two layers inside the Great Plains box. In addition to zero soil water (Fig. 6d), we have tested eight more prescribed values including $0.5,1.0,2.0,3.0,4.0,6.0,8.0$, and $10.0 \mathrm{~kg} \mathrm{~m}^{-2}$, respectively. For each value, we run a $100-$ member steady forcing experiment during May-August, and the seasonal averaged Z200 response from the nine cases is presented in Fig. 8.

First, a quick comparison of the extreme dry cases (Figs. 8a,b,c) with the extreme wet cases (Figs. 8g,h,i) seems to suggest that there is some linearity in the circulation response, in that the geopotential height anomalies in the midlatitudes have opposite sign in these two sets: positive Z200 anomalies in the dry cases and negative anomalies in the wet cases. This is especially true for the local response near the Great Plains box that is characterized by high (low) height anomalies centered at the northwest corner of the box for the dry (wet) cases. This attribute seems to support our intuition that the circulation response to surface sensible heat flux, through which soil moisture can influence the atmospheric circulation, in some ways obeys a general linearity property.

But there are also features that cannot be interpreted by a simple linear relationship. For example, when we compare the response away from the Great Plains box, the response pattern in the extreme wet cases does not resemble that in the extreme dry cases with the sign flipped. While Great Plains dryness forces high pressure anomalies at $40^{\circ}$ and $140^{\circ} \mathrm{E}$, Great Plains wetness induces one low pressure anomaly between $70^{\circ}$ and $100^{\circ} \mathrm{E}$ in the Russian far north and another at $180^{\circ}$.

When the prescribed soil water in the Great Plains box is closer to the range of the model's natural variability (e.g., $2.0-4.0 \mathrm{~kg} \mathrm{~m}^{-2}$ ) we hardly find any robust circumglobal teleconnection response (Figs. 8d,e,f). The ability for soil moisture feedbacks in the Great Plains to modify circulation under more natural conditions is discussed in section 6 .

\section{Formation of the summertime stationary wave response}

In this section we investigate how regionally prescribed soil water can trigger circumglobal circulation responses in the northern summer, by further analyzing the standard May-August Great Plains soil water depletion experiment shown in Fig. 1f.
To present the temporal evolution of the wave train response in the Northern Hemisphere midlatitudes in this experiment, we plot a Hovmöller diagram using daily ensemble mean Z200 anomalies averaged between $40^{\circ}$ and $60^{\circ} \mathrm{N}$ (Figs. 9b,c). Figure 9a is a replot of Fig. 1f with a different color bar. We stretch the Hovmöller diagram in the first 30 days (Fig. 9c) to get a closer look of how the wave train emerges in the midlatitudes. It takes about five days for the high pressure system to form over the Great Plains, immediately followed by the low pressure system at $60^{\circ} \mathrm{W}$, and the high pressure system at $30^{\circ} \mathrm{W}$. The two high pressure systems over Eurasia, which appear about two weeks after the forcing is imposed, take a slightly longer time to form. Once formed, both the high and low pressure anomalies are quite persistent till the end of the summer. Such a step-by-step development of the wave train is supported by a plot of the vertical cross section of geopotential height anomalies averaged at $40^{\circ}-60^{\circ} \mathrm{N}$ on days $5,10,15$, and 20 (Fig. 10). Also noteworthy is that the wave train has an almost barotropic structure, thus it is conceivable that this circumglobal wave train can influence surface climate along the wave path.

The spatial structure of the wave train is reminiscent of an atmospheric Rossby wave trapped along the midlatitude jet streams (Branstator 1983; Ambrizzi et al. 1995). Next we compute the horizontal component of the Rossby wave activity flux (Takaya and Nakamura 2001) for this response pattern to show the associated energy propagation, as the wave activity flux tends to be parallel to the group velocity of Rossby waves. The Rossby wave energy appears to emanate from the Great Plains on day 5 and converge into the Atlantic Ocean on day 10 , concurrent with the formation of the crossAtlantic wave train. Interestingly, compared to the Atlantic sector, there is a noticeable lack of wave activity flux before the high pressure system is established in the northern Eurasia from day 10 to day 15. We show later (Fig. 15) that synoptic eddies play a crucial role in forming this high pressure system. From day 15 to day 20 , the wave activity flux propagates from northern Eurasia across the Pacific Ocean. Once the wave activity encircles the globe on day 20, both the geopotential height anomalies (Figs. 11d and 9) and the surface temperature anomalies (Fig. 11d) over North America intensify. This intensification suggests that having a circumglobal structure may amplify stationary wave anomalies through positive interference between the locally forced disturbances and disturbances propagating into North America from the west. Note, however, that some stationary waves observed during extreme events are not circumglobal (Fragkoulidis et al. 2018). 


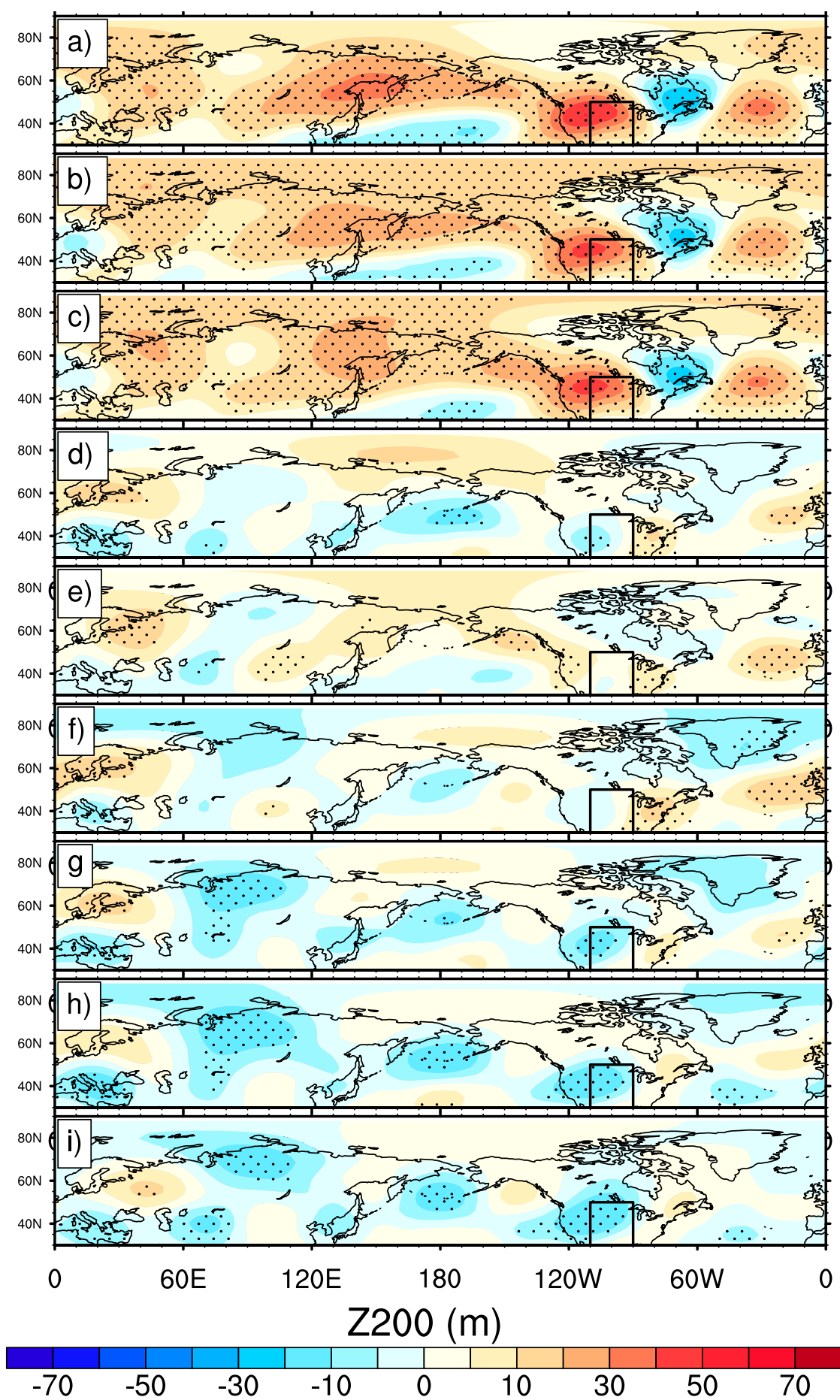

FIG. 8. Seasonal mean Z200 response when soil water in the top two layers $(3.5 \mathrm{~cm})$ is prescribed to (a) 0, (b) 0.5, (c) 1.0, (d) 2.0, (e) 3.0, (f) 4.0, (g) 6.0, (h) 8.0, and (i) $10.0 \mathrm{~kg} \mathrm{~m}^{-2}$ in the Great Plains box during May-August. Stippling represents the $95 \%$ confidence level with a Student's $t$ test.

We also notice a second wave train emanating from the Mediterranean to Pakistan on day 20 (Fig. 11d), although the amplitude of both the height anomalies and the wave activity flux is much weaker compared to those in northern Eurasia. Associated with the double jet core in the Atlantic sector, there are two main waveguides linking the North Atlantic and Eurasia (Hoskins and Ambrizzi 1993; Ambrizzi et al. 1995). 

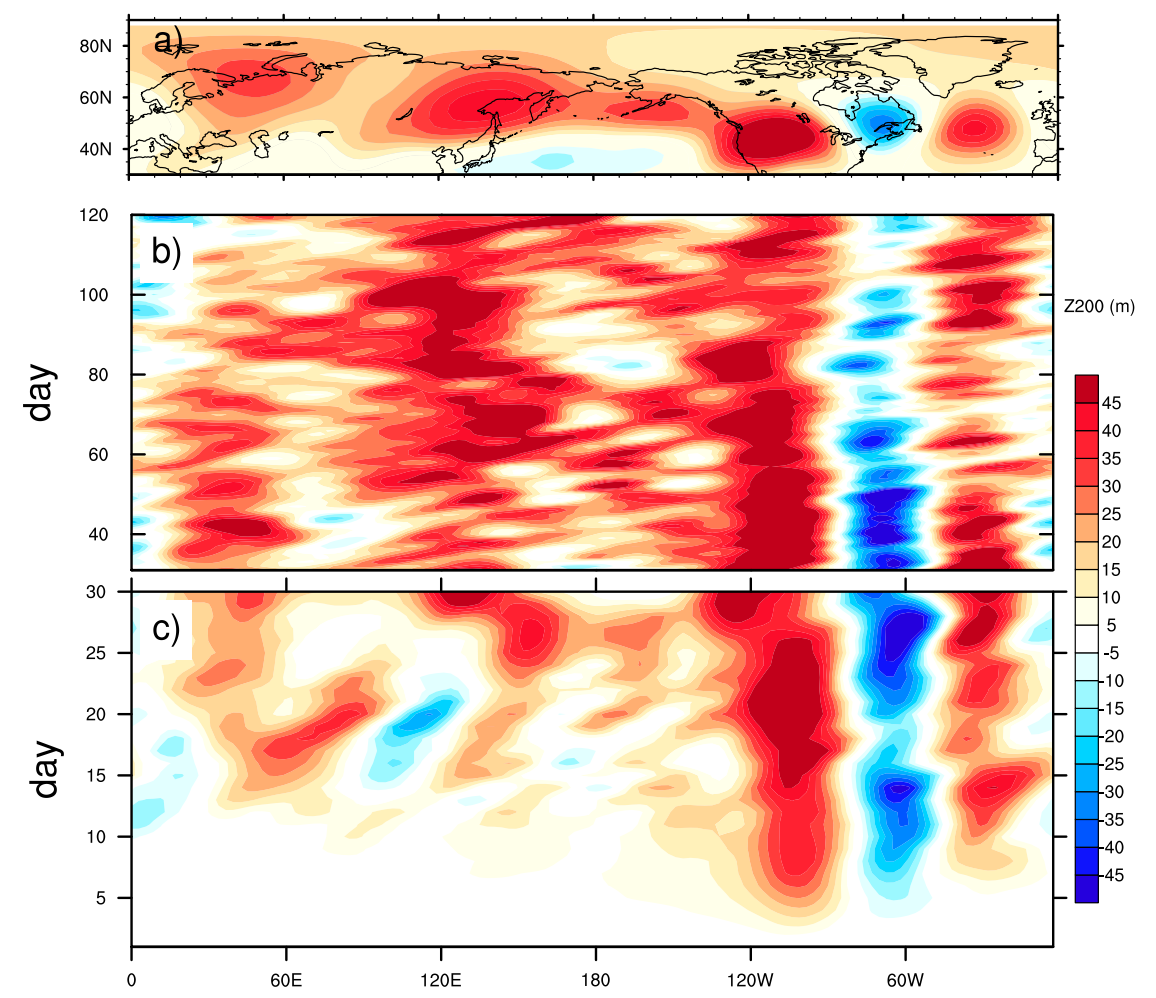

FIG. 9. (a) Seasonal mean response of Z200 in the Great Plains soil water depletion experiment in May-August (replot of Fig. If with a different color bar). (b),(c) Hovmöller diagrams of daily Z200 averaged at $40^{\circ}-60^{\circ} \mathrm{N}$. Note the time scale is different in (b) and (c).

One tilts northeastward from the U.S. east coast to Scandinavia, and the other stretches from the subtropical eastern Atlantic and the Mediterranean all the way to the North Pacific Ocean. In the Great Plains experiment, the southern waveguide seems rather weak, which may be caused by the mean flow in May. When we delay the start dates of the soil moisture experiments to the first day of July and August (Fig. 3), the response in the southern waveguide (e.g., the high pressure anomalies near the Caspian Sea) becomes stronger, and the global response resembles an observed wavenumber-5 CGT pattern (Ding and Wang 2005; Lee et al. 2017). Such behavior also supports Ding and Wang's (2005) finding that the wavenuber-5 CGT pattern is most pronounced in August compared to other summer months in nature.

After learning about the temporal evolution of the forced response, next we want to consider the mechanisms by which the imposed dryness in the Great Plains can excite a circumglobal wave train response. First, we calculate diabatic heating anomalies caused by the imposed dryness.

The 100-member ensemble mean and \pm 1 standard deviation of the total diabatic heating anomalies horizontally averaged in the Great Plains box during May-August for the zero soil moisture experiment are represented by the red solid and dotted lines, respectively, in Fig. 12. Near the surface the warming is about $4^{\circ} \mathrm{Cday}^{-1}$ and then decreases almost linearly to $700 \mathrm{hPa}$. In CESM1, the diabatic heating rate is calculated as the sum of the temperature tendency due to vertical diffusion (DTV), longwave heating (QRL), solar heating (QRS), and moisture processes (DTCOND), which are also plotted in Fig. 12. In our experiments, the near-surface warming is mainly caused by enhanced vertical diffusion and longwave heating, compensated by reduced shortwave and condensational heating (Fig. 12b). The vertical diffusion becomes much weaker in the winter as a result of weaker boundary layer turbulence (Fig. 12a), and the total diabatic heating anomalies are reduced to $1^{\circ} \mathrm{Cday}^{-1}$ at the near surface accordingly when we impose the same dryness in the Great Plains box during November-February.

To further verify that the diabatic heating anomalies caused by the imposed dryness in the Great Plains can excite the circumglobal response, we use a technique that is similar to Koster et al. (2016), except that we 


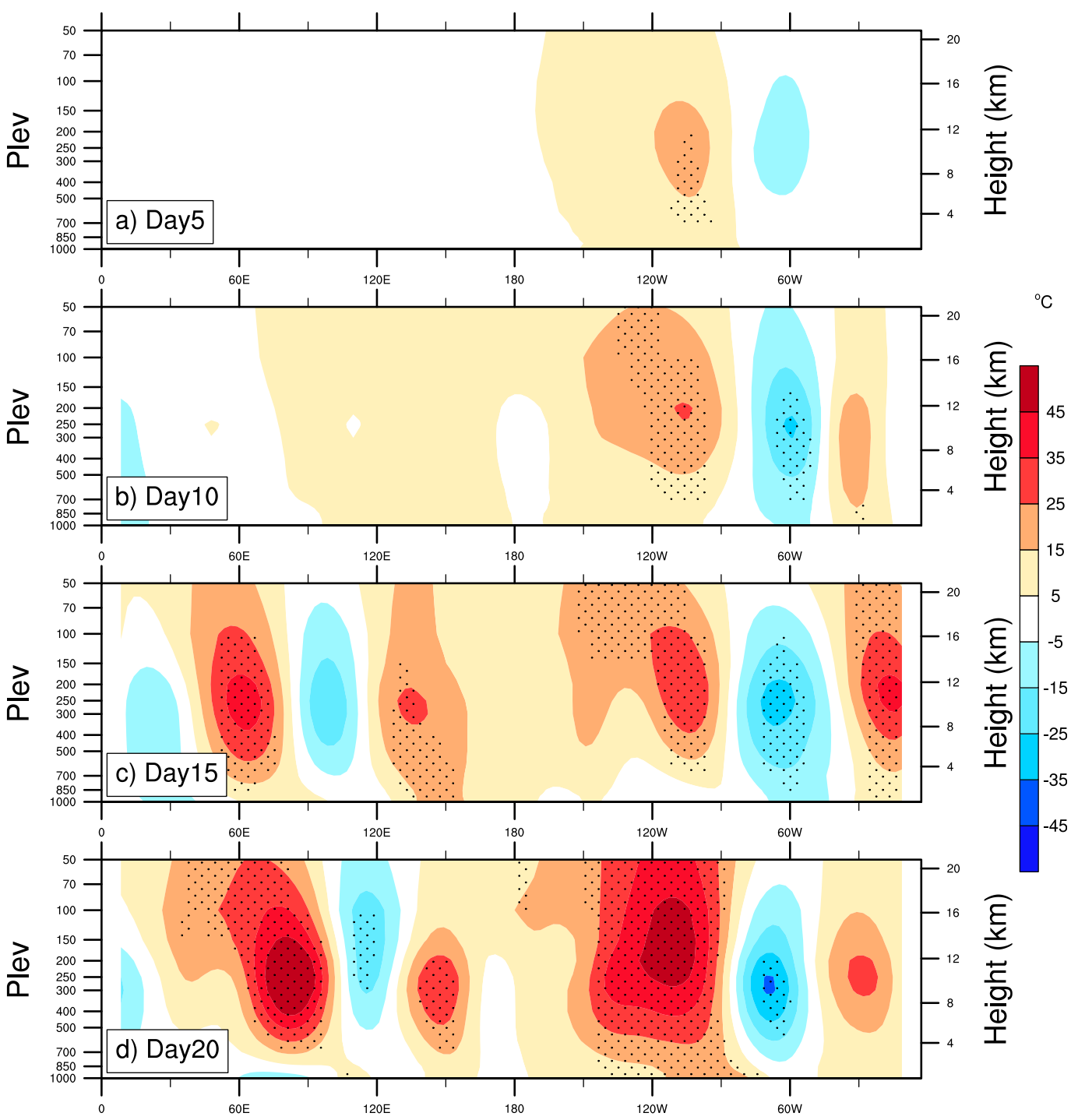

FIG. 10. Vertical cross section of geopotential height anomalies at $40^{\circ}-60^{\circ} \mathrm{N}$ on (a) day 5 , (b) day 10 , (c) day 15 , and (d) day 20 from the Great Plains soil water depletion experiment in May-August. Stippling represents the $95 \%$ confidence level with a Student's $t$ test.

apply the heating anomalies to a GCM rather than a simple model. We have carried out three CAM5 experiments for the period of May-August; each experiment consists of 100 members.

The only difference between these experiments and the CAM5 control run is that steady heating anomalies are imposed in the Great Plains box. These imposed heating anomalies are based on time-averaged MayAugust diabatic heating anomalies from the zero soil moisture experiment. In the first experiment, we retain both the spatial and vertical structure of the diabatic heating anomalies within the Great Plains box, which are replaced with the domain-averaged heating profile (Fig. 12b) in the second experiment. Then we further simplify the heating profile by only keeping the onedimensional heating anomalies from the surface to roughly $700 \mathrm{hPa}$ in the third experiment.

Despite the approximations in the imposed heating, all three experiments can replicate the seasonal mean Z200 response to the imposed dryness in the Great Plains (Figs. 13a). For the sake of brevity, we only present the Z200 response in the third experiment (Fig. 13b) which has the most simplified heating. The resemblance between the two panels is striking, suggesting that the heating anomalies in the lower troposphere are sufficient to produce the circumglobal circulation response and the response is not sensitive to the fine horizontal structure of the heating anomalies. 


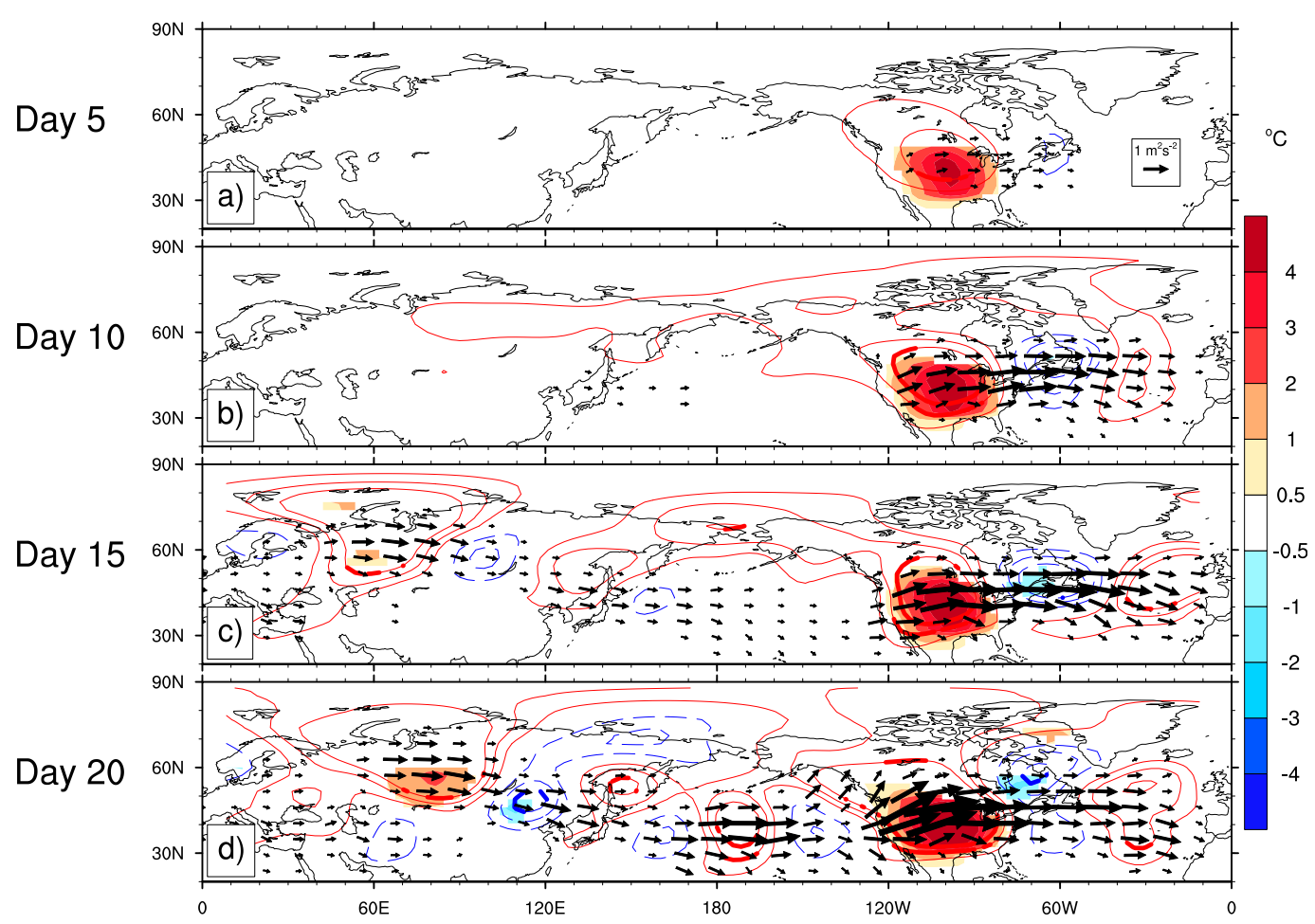

FIG. 11. Response of Z200 (contours; intervals of $\pm 10,20$, and $30 \mathrm{~m}$ ), surface air temperature (TAS; shading), and horizontal component of wave activity flux $\left(\mathrm{m}^{2} \mathrm{~s}^{-2}\right)$ at $200 \mathrm{hPa}$ on (a) day 5, (b) day 10, (c) day 15, and (d) day 20 in the May-August Great Plains soil water depletion experiment.

Next, we want to isolate the direct linear response to the heating due to the waveguide effect. To do that, we impose the same heating profile from surface to approximately $700 \mathrm{hPa}$ (Fig. 13b) in the linear planetary wave model that we have introduced earlier. The streamfunction response in the upper troposphere (at the 0.25 sigma level; Fig. 14a) mainly comprises the anticyclonic circulation anomalies in North America, cyclonic circulation anomalies farther to the northeast, and anticyclonic circulation anomalies to the south of Greenland. While it is reassuring that our result generally agrees with Koster et al. (2016), who employed a different planetary wave model, what is of more interest is the apparent difference between the responses from the linear model (Fig. 14a) and from the GCM (Fig. 13a).

Among all the missing physical and dynamical processes that could be responsible for this discrepancy in the linear stationary wave model solution, we have focused on synoptic eddies. To determine whether synoptic eddies can make a significant contribution to the stationary wave response, we use a technique that has been employed by many previous studies (Cai and Mak 1990; Cai and van den Dool 1994; Feldstein 1998) that is based on the vorticity equation:

$$
\frac{\partial \zeta}{\partial t}+\mathbf{V} \cdot \nabla(f+\zeta)+(f+\zeta) \nabla \cdot \mathbf{V}=0
$$

where $\zeta, t, f$, and $\mathbf{V}$ stand for relative vorticity, time, the Coriolis parameter, and horizontal wind, respectively. We decompose all variables in Eq. (1) into 2-8-day high-pass filtered transients, $>8$-day low-frequency, and climatology components and derive the vorticity equation for the low-frequency flow [Eq. (4) of Cai and van den Dool (1994)]. The low-frequency vorticity tendency induced by transient eddies is expressed as $\left(-\mathbf{V}^{\prime}{ }_{\psi} \cdot \nabla \zeta^{\prime}\right)^{S}$, where the superscript $S$ and prime refer to the seasonal average and 2-8-day high pass filtering, respectively, and $\mathbf{V}_{\psi}$ denotes the rotational wind.

Applying a reverse Laplacian operator on both sides of the low-frequency vorticity tendency equation, we convert the vorticity tendency equation into a streamfunction tendency equation for the low-frequency component. The transient eddy forcing now becomes $\nabla^{-2}\left(-\mathbf{V}_{\psi}^{\prime} \cdot \nabla \zeta^{\prime}\right)^{S}$, which is a familiar term that has been examined in many previous studies (Cai and Mak 1990; Cai and van den Dool 1994; Branstator 1995) to account for the nonlinear interaction between low-frequency and transient eddies.

Figure 15 shows the streamfunction anomalies in our standard Great Plains prescribed soil moisture experiment 

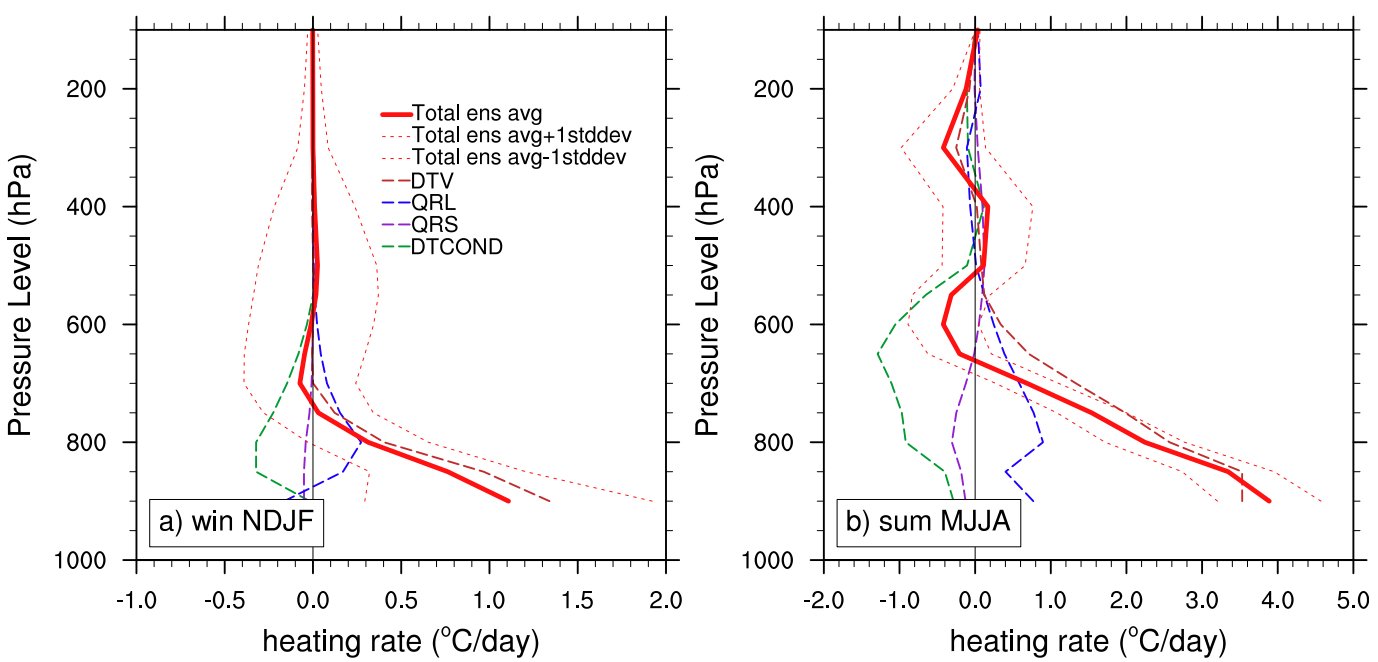

FIG. 12. Vertical profile of seasonal mean diabatic heating anomalies for the (a) November-February and (b) May-August soil water depletion experiments at the Great Plains box. The solid and dotted red lines represent the 100-member ensemble mean and \pm 1 standard deviation, respectively. The four colored dashed lines represent the ensemble averaged terms that contribute to the total diabatic heating rate: DTV (vertical diffusion tendency), QRL (longwave heating rate), QRS (solar heating rate), and DTCOND (precipitation physics tendency).

(contours) and the streamfunction tendency induced by the transient vorticity flux $\nabla^{-2}\left(-\mathbf{V}_{\psi}^{\prime} \cdot \nabla \zeta^{\prime}\right)^{S}$ (shading). Here both terms are averaged through May-August and are evaluated at $200 \mathrm{hPa}$. As expected, the wave pattern expressed in terms of the streamfunction anomalies closely resembles that in Z200. The synoptic eddy forcing is strongest along the storm tracks in both the Pacific and the Atlantic Oceans. When we compare the signs of the streamfunction anomalies with that of the streamfunction tendency induced by the eddies, it is apparent that at both jet exit regions the eddies help to maintain the lowfrequency wave train.

To further quantify the eddy contribution to the seasonal mean circulation response, we again use the linear planetary wave model, except that this time we use the model to derive the steady solution to the eddy vorticity

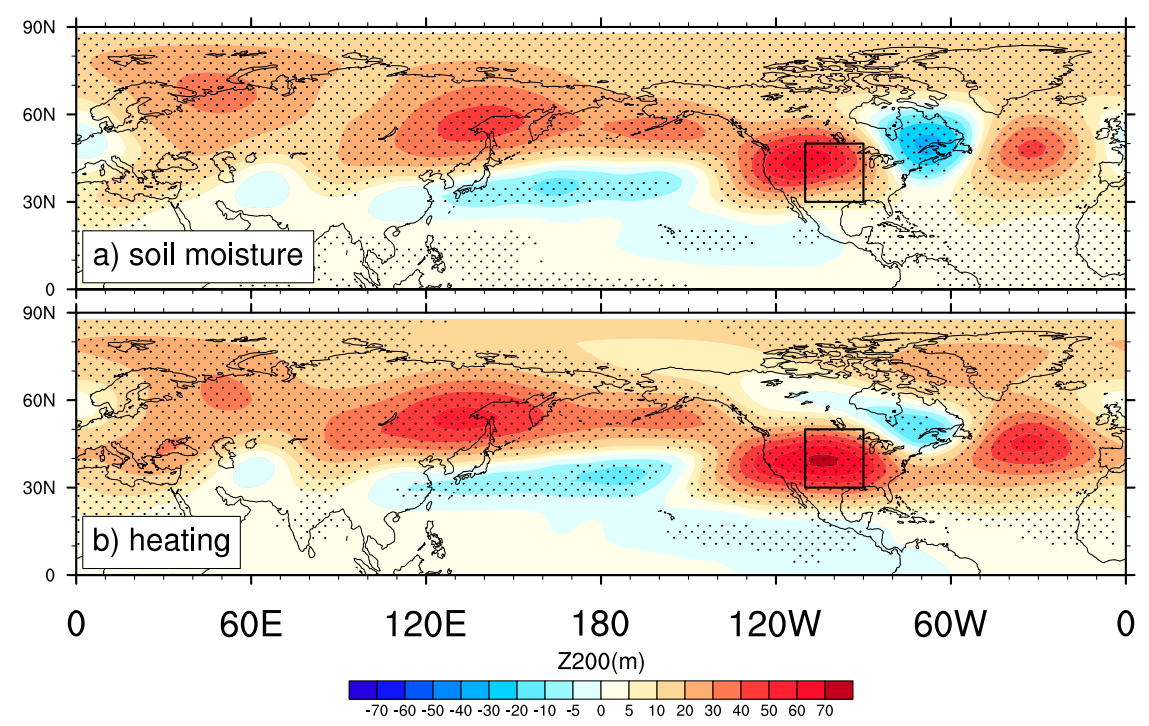

FIG. 13. Seasonal mean Z200 response from (a) the Great Plains soil water depletion experiment and (b) imposed heating experiment, where the heating anomalies in Fig. 12b are imposed in CAM5 from the surface to $700 \mathrm{hPa}$ in the Great Plains box during May-August. Stippling represents the $95 \%$ confidence level with a Student's $t$ test. 


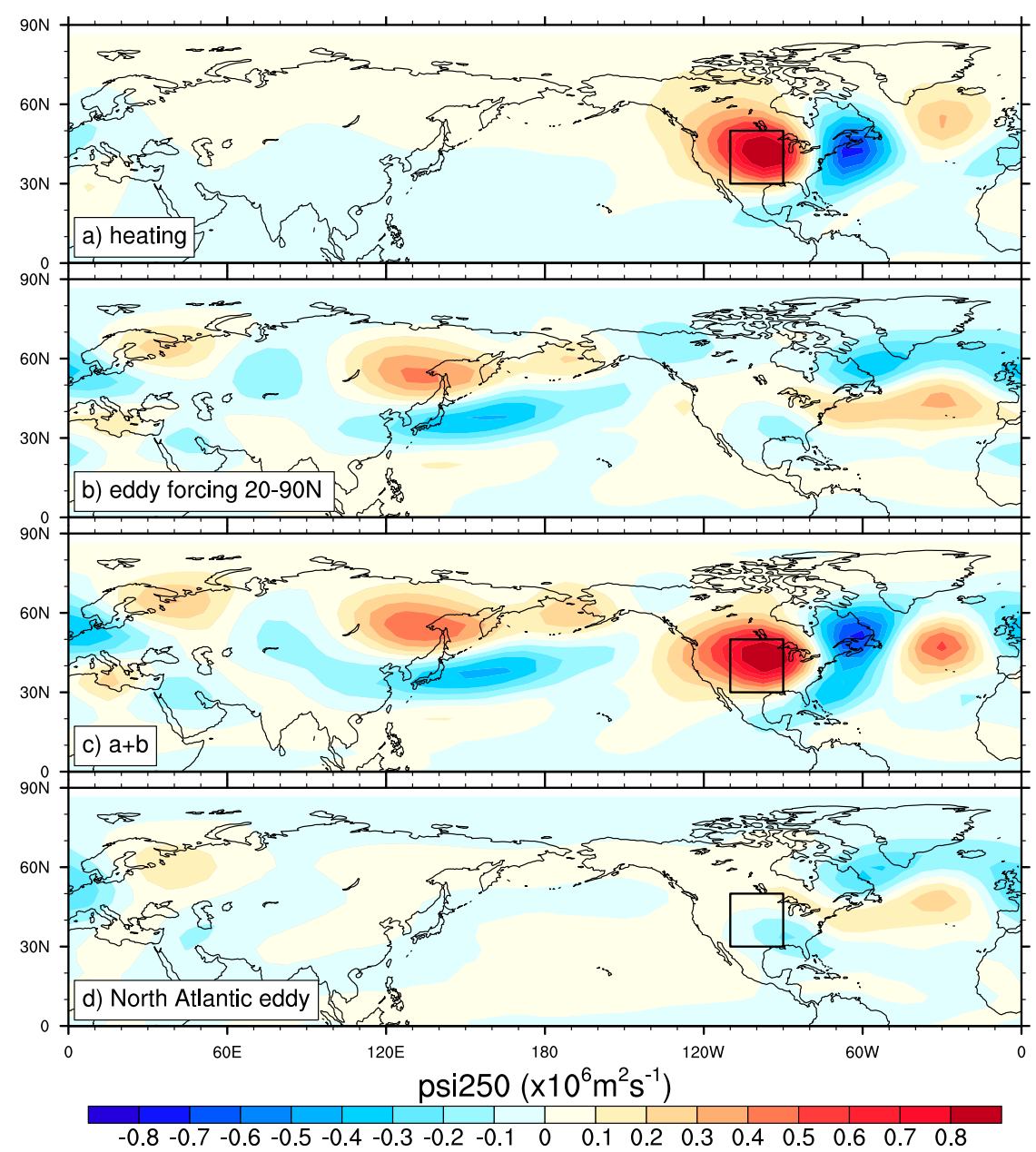

FIG. 14. Linear stationary wave response of the streamfunction at the $\sigma=0.250$ level (PSI250) to (a) the heating anomalies from surface to $700 \mathrm{hPa}$ (Fig. 12b) in the Great Plains box and (b) synoptic eddy vorticity forcing at $20^{\circ}-90^{\circ} \mathrm{N}$. (c) The sum of (a) and (b). (d) As in (b), but for eddy vorticity forcing at $120^{\circ} \mathrm{W}-0^{\circ}, 20^{\circ}-90^{\circ} \mathrm{N}$. Both heating and synoptic eddy vorticity forcings are derived from the Great Plains soil water depletion experiments in MayAugust.

forcing $\left(-\mathbf{V}^{\prime}{ }_{\psi} \cdot \nabla \zeta^{\prime}\right)^{S}$ at all 10 sigma levels within $20^{\circ}-$ $90^{\circ} \mathrm{N}$ derived from the CAM5 simulations. The streamfunction solution at the 0.25 sigma level has a zonally elongated dipole structure at the jet exit region in both the Pacific and the Atlantic Ocean sectors (Fig. 14b). More interestingly, the response contains positive anomalies over northern Eurasia and the Far East, similar to the response in the CAM5 experiments (Fig. 15). After combining contributions from the synoptic eddy vorticity forcing (Fig. 14b) with the direct linear response to the Great Plains heating (Fig. 14a), the sum (Fig. 14c) reproduces the main features of the "circumglobal" structure in the CAM5 response (Fig. 15). Additional tests with the linear model using the eddy vorticity forcing from different geographic sectors further shows that transients over both the Atlantic Ocean and Eurasia contribute to the response in Fig. 14b. For example, Fig. 14d shows the linear model response to the synoptic eddy forcing at $120^{\circ} \mathrm{W}-0^{\circ}$ and $20^{\circ}-90^{\circ} \mathrm{N}$. By comparing Fig. 14b and Fig. 14d, one sees that a large portion of the positive anomalies over northern Europe at $30^{\circ}-60^{\circ} \mathrm{E}$ can be explained by anomalous synoptic eddy forcing in the North America and North Atlantic sector. The anomalous eddy forcing in that region is likely to be a reaction to the wave train (Fig. 14a) directly forced by the Great Plains heating anomaly. Hence the two-way interaction between the wave and synoptic eddy response is acting to amplify and extend the response to Great Plains conditions. While other processes that we have not considered (e.g., eddy heat fluxes) may also be involved, our experiments do indicate that the CGT response cannot be fully explained by the waveguide effect of the mean climate 


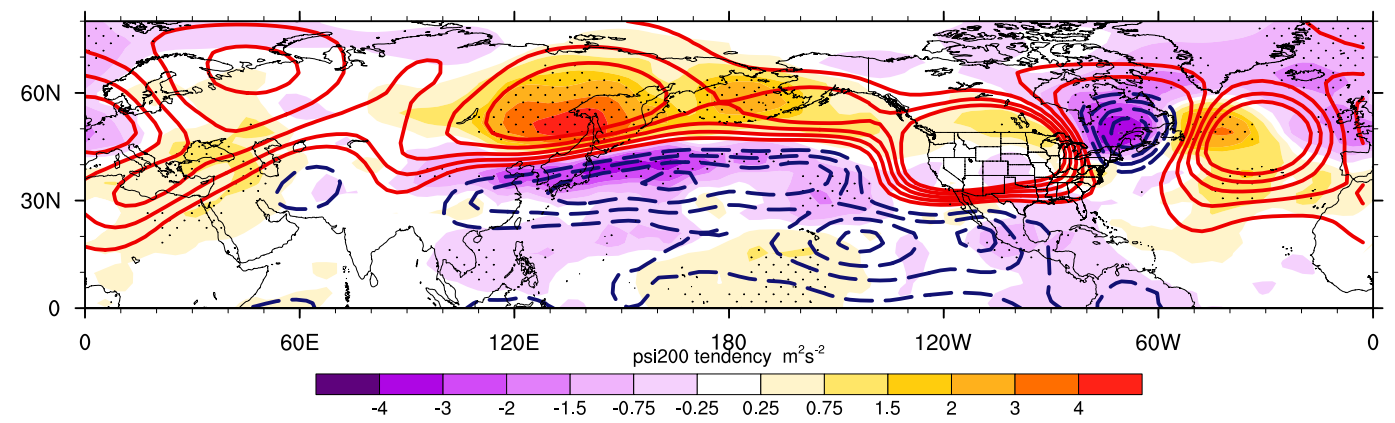

FIG. 15. Seasonal mean response of the 200-hPa streamfunction (PSI200; contours at $\pm 0.25,0.75,1.5,2,3$, and $4 \times 10^{6} \mathrm{~m}^{2} \mathrm{~s}^{-1}$ ) and synoptic eddies' contribution to the seasonal mean PSI200 tendency (shading) averaged for May-August from the Great Plains soil water depletion experiments. Stippling represents where synoptic eddy forcing is significantly different (at the $95 \%$ confidence level) from the control run with a Student's $t$ test.

states because transient eddy vorticity fluxes play a vital role in extending the response beyond the source region.

\section{Conclusions}

Motivated by the apparent increase in the frequency of high-impact circumglobal stationary wave events in the recent boreal summers, we have carried out a series of idealized prescribed soil moisture experiments with the atmosphere/land stand-alone configuration of CESM1 to investigate the potential contribution that the drier soil moisture that accompanies a warmer climate can make to these events. We started by prescribing the soil water within four large selected domains in the continental United States to be zero and running 100 -member ensemble experiments to assess the seasonal mean response. To determine the robustness of our findings, we carried out additional experiments to examine the sensitivity of the response to 1) the location of the forcing among 21 subdomains within the continental United States, 2) various depths where soil water is depleted, and 3) the value of the prescribed soil water. In addition, we have replaced the steady soil water forcing with forcing lasting only a month to evaluate whether the persistence of the forcing is crucial. We have learned the following:

1) The imposed dryness in the continental United States can excite a robust circumglobal teleconnection response in the boreal summer, while it is hard to produce a robust and consistent response when the same experiment is conducted in the wintertime.

2) The location of the ridges and troughs of the stationary wave response is generally insensitive to where dryness is imposed within the continental United States.

3) Removal of soil water in just the top two layers $(\sim 3 \mathrm{~cm})$ in the Great Plains is sufficient to produce a robust circumglobal circulation response.
4) The 1-month short-lived forcing in the Great Plains can cause a delayed circumglobal circulation response later in the summer as well as in the following winter, although the delayed winter response does not resemble a waveguide teleconnection pattern.

A key finding from this study is that an extremely dry Great Plains can excite CGT patterns in the boreal summer through the near-surface heating anomalies $\left(\sim 4^{\circ} \mathrm{C} \mathrm{day}^{-1}\right.$ in our experiments) caused by the dry soil. The direct circulation response to the heating anomalies, via linear adiabatic dynamical processes in the midlatitude, including the waveguide effect of the mean jet streams, is mainly confined to North America and the North Atlantic Ocean. However, through eddy-mean flow interactions, perturbed synoptic eddies can contribute greatly to a remote stationary wave response in Eurasia and the North Pacific Ocean, leading to a circumglobal response to the regional land forcing.

This cause-and-effect relationship between the Great Plains heating anomalies and the CGT response, which is confirmed by additional CAM5 heating experiments, adds to our understanding of the forcing mechanisms for CGT. Earlier, Ding and Wang (2005) speculated that the heating anomalies associated with the Indian summer monsoon are instrumental in maintenance of the CGT, whereas, with a different definition for CGT, Yasui and Watanabe (2010) stress the role of internal dynamics rather than tropical forcing. Here, with a comprehensive perturbed large ensemble approach, we provide a convincing example that a midlatitude forcing can also excite CGT. Keeping in mind that the Great Plains and the Indian summer monsoon region are the two locations with the strongest waveguide teleconnectivity in the boreal summer (Branstator and Teng 2017), it is not surprising that our study and previous ones (Ding and Wang 2005; Yasui and Watanabe 


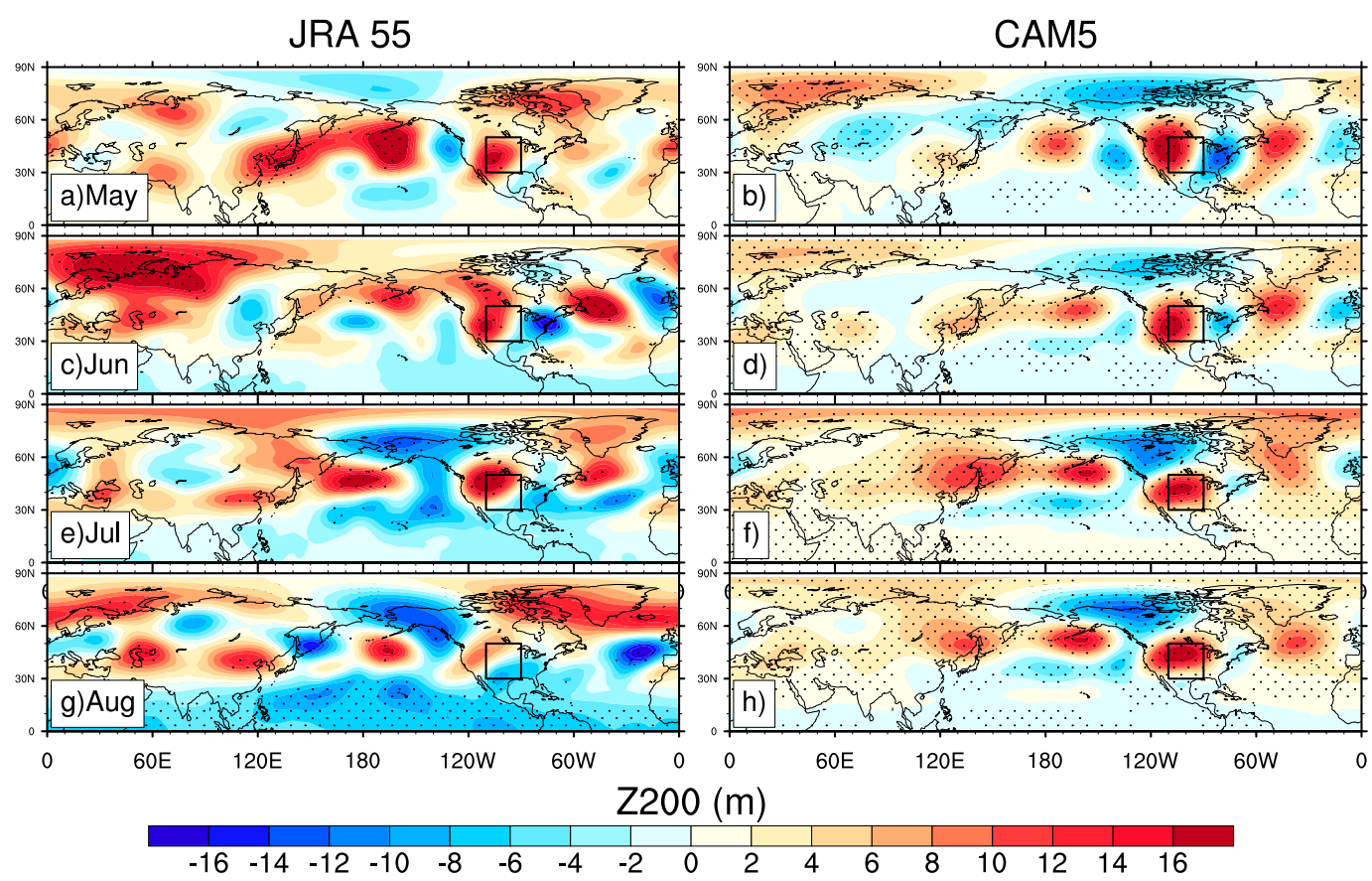

FIG. 16. Regressed Z200 upon domain averaged soil moisture in the Great Plains box in (left) JRA-55 and (right) the 2600-yr CAM5 control run during (a),(b) May, (c),(d) June, (e),(f) July, and (g),(h) August. Stippling represents the $90 \%$ confidence level with a Student's $t$ test.

2010) have found that forcing near these locations is effective at generating a circumglobal response.

Since our finding is derived from idealized experiments with a GCM, one may question whether it has real implications. Indeed we find some initial evidence from the reanalysis data that supports the relationship between soil moisture and the circulation. In the left panels of Fig. 16, we regress the monthly Z200 anomalies upon domain-averaged soil moisture in the Great Plains box in May, June, July and August, respectively, using the Japanese 55-yr Reanalysis (JRA-55; Kobayashi et al. 2015). For comparison, we plot the Z200 regressed anomalies in the 2600-yr CAM5 control run in the right panels of Fig. 16. Despite the relatively short reanalysis data, soil moisture anomalies in the Great Plains box seem to be associated with a circumglobal wave train in all four months; also, importantly, the wave trains bear some resemblance to the CAM5 counterpart. Because such statistical relationship cannot deliver any information on cause and effect, in order to make a more convincing argument we need to carry out case studies (e.g., Fischer et al. 2007; Wang et al. 2017) targeting some observed extreme events.

Second, many hypotheses for amplified stationary wave anomalies in the recent decades [reviewed by Hoskins and Woollings (2015) and Barnes and Screen (2015)] are based on an assumption of a connection between stationary wave anomalies and the mean dynamical or thermodynamical fields. Among them, the so-called "quasi-resonant amplification" (QRA; Petoukhov et al. 2013; Mann et al. 2018) proposes that the mean structure change in the jets (double jets) due to climate change can enhance the "waveguidability" of the jets and amplify circumglobal planetary wave anomalies. Our study indicates that the weak summer waveguides are insufficient to produce the circumglobal feature of stationary wave anomalies in the summer even when a relatively strong forcing is imposed. To capture and fully explain the circumglobal wave anomalous in the summer, realistic representation of the mean waveguide structure (Kosaka et al. 2009) is not enough. Synoptic eddies play a crucial role in the summertime CGT and must be accurately simulated as well.

Aside from these implications, we must acknowledge a couple of limitations in this study. One is that the soil moisture anomalies that we have imposed in experiments that produced significant circulation responses are unrealistically strong. This was indicated in section $4 d$ where we explained that only when the prescribed soil water falls outside the range of the model's natural variability can the model produce a robust circulation response. On the other hand, even though Koster et al. (2016) employed a more realistic approach to imposing soil dryness than we employed, the near-surface heating anomalies that were generated in their experiments are 
quite similar to ours in terms of both amplitude and vertical structure. Thus, from the perspective of atmospheric forcing, the anomalies we imposed may not be as unrealistic as they appear to be from the perspective of soil moisture. When we designed the experiments, removal of soil water in the top $3 \mathrm{~cm}$ did not seem far-fetched for an idealized experiment designed to mimic a "dust bowl" scenario (Schubert et al. 2004). While carrying out our project, we became more aware of the relatively large biases and uncertainties in atmosphere-land coupling in such models (Dirmeyer et al. 2006, Williams et al. 2016). Hence it may be that parameterizations in CESM are inadequate for producing so-called dust bowls in the control experiment that we analyzed. Our next step would be investigating with the reanalysis data the relationship between soil moisture and diabatic heating anomalies, which can be a key to understand to what extent the mechanism based on our idealized experiments can explain the increased high-impact circumglobal stationary wave events in the recent boreal summers.

Acknowledgments. This study was supported by the Regional and Global Model Analysis (RGMA) component of the Earth and Environmental System Modeling Program of the U.S. Department of Energy's (DOE) Office of Biological and Environmental Research (BER) Cooperative Agreement DE-FC02-97ER62402, and the National Science Foundation (NSF). Computing resources were provided by the Climate Simulation Laboratory at NCAR's Computational Information Systems Laboratory (doi:10.5065/D6RX99HX), sponsored by the NSF and other agencies, and by the National Energy Research Scientific Computing Center, a DOE Office of Science User Facility supported by the Office of Science of the U.S. DOE under Contract DE-AC02-05CH11231. GB acknowledges supports by NOAA MAPP NA14OAR4310224. NCAR is sponsored by the NSF. Output from the CESM1 large ensemble project was post-processed by Gary Strand and is available from the Earth System Grid (http:// www.earthsystemgrid.org).

\section{REFERENCES}

Ambrizzi, T., B. J. Hoskins, and H.-H. Hsu, 1995: Rossby wave propagation and teleconnection patterns in the austral winter. J. Atmos. Sci., 52, 3661-3672, https://doi.org/10.1175/15200469(1995)052<3661:RWPATP $>2.0$.CO 2 .

Barnes, E. A., and J. A. Screen, 2015: The impact of Arctic warming on the midlatitude jet-stream: Can it? Has it? Will it? Wiley Interdiscip. Rev.: Climate Change, 6, 277-286, https:// doi.org/10.1002/wcc.337.

Branstator, G., 1983: Horizontal energy propagation in a barotropic atmosphere with meridional and zonal structure J. Atmos. Sci., 40, 1689-1708, https://doi.org/10.1175/15200469(1983)040<1689:HEPIAB > 2.0.CO;2.
_ 1990: Low-frequency patterns induced by stationary waves. J. Atmos. Sci., 47, 629-649, https://doi.org/10.1175/15200469(1990)047<0629:LFPIBS > 2.0.CO;2.

_ 1992: The maintenance of low-frequency atmospheric anomalies. J. Atmos. Sci., 49, 1924-1946, https://doi.org/ 10.1175/1520-0469(1992)049<1924:TMOLFA > 2.0.CO;2.

1995: Organization of storm track anomalies by recurring low-frequency circulation anomalies. J. Atmos. Sci., 52, 207-226, https://doi.org/10.1175/1520-0469(1995)052<0207: OOSTAB $>2.0 . \mathrm{CO} ; 2$.

2002: Circumglobal teleconnections, the jet stream waveguide, and the North Atlantic Oscillation. J. Climate, 15, 1893-1910, https://doi.org/10.1175/1520-0442(2002) 015<1893:CTTJSW > 2.0.CO;2.

- and H. Teng, 2017: Tropospheric waveguide teleconnections and their seasonality. J. Atmos. Sci., 74, 1513-1532, https:// doi.org/10.1175/JAS-D-16-0305.1.

Cai, M., and M. Mak, 1990: Symbiotic relation between planetary and synoptic-scale waves. J. Atmos. Sci., 47, 2953-2968, https://doi.org/10.1175/1520-0469(1990)047<2953:SRBPAS> 2.0.CO;2.

_, and H. M. van den Dool, 1994: Dynamical decomposition of lowfrequency tendencies. J. Atmos. Sci., 51, 2086-2100, https:// doi.org/10.1175/1520-0469(1994)051<2086:DDOLFT>2.0.CO;2.

Conil, S., H. Douville, and S. Tyteca, 2007: The relative influence of soil moisture and SST in climate predictability explored within ensembles of AMIP type experiments. Climate Dyn., 28, 125-145, https://doi.org/10.1007/s00382006-0172-2.

Ding, Q., and B. Wang, 2005: Circumglobal teleconnection in the Northern Hemisphere summer. J. Climate, 18, 3483-3505, https://doi.org/10.1175/JCLI3473.1.

Dirmeyer, P. A., 2005: The land surface contribution to the potential predictability of boreal summer season climate. J. Hydrometeor., 6, 618-632, https://doi.org/10.1175/JHM444.1.

, R. D. Koster, and Z. Guo, 2006: Do global models properly represent the feedback between land and atmosphere? J. Hydrometeor., 7, 1177-1198, https://doi.org/10.1175/JHM532.1. , and Coauthors, 2012: Evidence for enhanced landatmosphere feedback in a warming climate. J. Hydrometeor., 13, 981-995, https://doi.org/10.1175/JHM-D-11-0104.1.

Douville, H., 2002: Influence of soil moisture on the Asian and African monsoon. Part II: Interannual variability. J. Climate, 15, 701-720, https://doi.org/10.1175/1520-0442(2002)015<0701: IOSMOT $>2.0 . \mathrm{CO} ; 2$.

, and F. Chauvin, 2000: Relevance of soil moisture for seasonal climate predictions: A preliminary study. Climate Dyn., 16, 719-736, https://doi.org/10.1007/s003820000080.

—, J. Colin, E. Krug, J. Cattiaux, and S. Thao, 2016: Midlatitude daily summer temperature reshaped by soil moisture under climate change. Geophys. Res. Lett., 43, 812-818, https:// doi.org/10.1002/2015GL066222.

Ek, M. B., and A. A. M. Holtslag, 2004: Influence of soil moisture on boundary layer cloud development. J. Hydrometeor., 5, 86-99, https:// doi.org/10.1175/1525-7541(2004)005<0086:IOSMOB >2.0.CO;2.

Feldstein, S., 1998: The growth and decay of low-frequency anomalies in a GCM. J. Atmos. Sci., 55, 415-428, https://doi.org/ 10.1175/1520-0469(1998)055<0415:TGADOL > 2.0.CO;2.

Findell, K. L., and E. A. B. Eltahir, 2003: Atmospheric controls on soil moisture-boundary layer interactions: Part I: Framework development. J. Hydrometeor., 4, 552-569, https://doi.org/ 10.1175/1525-7541(2003)004<0552:ACOSML>2.0.CO;2. 
Fischer, E. M., S. I. Seneviratne, P. L. Vidale, D. Lüthi, and C. Schär, 2007: Soil moisture-atmosphere interaction during the 2003 European summer heat waves. J. Climate, 20, 50815099, https://doi.org/10.1175/JCLI4288.1.

_ J. Rajczak, and C. Schär, 2012: Changes in European summer temperature variability revisited. Geophys. Res. Lett., 39, L19702, https://doi.org/10.1029/2012GL052730.

Fragkoulidis, G., V. Wirth, P. Bossmann, and A. H. Fink, 2018: Linking Northern Hemisphere temperature extremes to Rossby wave packets. Quart. J. Roy. Meteor. Soc., 144, 553566, https://doi.org/10.1002/qj.3228.

Gentine, P., A. A. Holtslag, F. D'Andrea, and M. Ek, 2013: Surface and atmospheric controls on the onset of moisture convection over land. J. Hydrometeor., 14, 1443-1462, https://doi.org/ 10.1175/JHM-D-12-0137.1.

Guillod, B. P., B. Orlowsky, D. G. Miralles, A. J. Teuling, and S. I. Seneviratne, 2015: Reconciling spatial and temporal soil moisture effects on afternoon rainfall. Nat. Commun., 6, 6443, https://doi.org/10.1038/ncomms7443.

Horton, D. E., N. C. Johnson, D. Singh, D. L. Swain, B. Rajaratnam, and N. S. Diffenbaugh, 2015: Contribution of changes in atmospheric circulation patterns to extreme temperature trends. Nature, 522, 465-469, https://doi.org/ 10.1038/nature14550.

Hoskins, B. J., and T. Ambrizzi, 1993: Rossby wave propagation on a realistic longitudinally varying flow. J. Atmos. Sci., 50, 1661-1671, https://doi.org/10.1175/1520-0469(1993)050<1661: RWPOAR $>2.0 . \mathrm{CO} ; 2$.

— , and T. Woollings, 2015: Persistent extratropical regimes and climate extremes. Curr. Climate Change Rep., 1, 115-124, https://doi.org/10.1007/s40641-015-0020-8.

— A. J. Simmons, and D. G. Andrews, 1977: Energy dispersion in a barotropic atmosphere. Quart. J. Roy. Meteor. Soc., 103, 553-567, https://doi.org/10.1002/qj.49710343802.

Hurrell, J., and Coauthors, 2013: The Community Earth System Model: A framework for collaborative research. Bull. Amer. Meteor. Soc., 94, 1339-1360, https://doi.org/10.1175/BAMS-D12-00121.1.

Kay, J. E., and Coauthors, 2015: The Community Earth System Model (CESM) Large Ensemble Project: A community resource for studying climate change in the presence of internal climate variability. Bull. Amer. Meteor. Soc., 96, 1333-1349, https://doi.org/10.1175/BAMS-D-13-00255.1.

Kobayashi, S., and Coauthors, 2015: The JRA-55 Reanalysis: General specifications and basic characteristics. J. Meteor. Soc. Japan, 93, 5-48, https://doi.org/10.2151/jmsj.2015001.

Kosaka, Y., H. Nakamura, M. Watanabe, and M. Kimoto, 2009: Analysis of the dynamics of a wave-like teleconnection pattern along the summertime Asian jet based on a reanalysis dataset and climate model simulations. J. Meteor. Soc. Japan, 87, 561-580, https://doi.org/10.2151/jmsj. 87.561.

Koster, R. D., and Coauthors, 2004: Regions of strong coupling between soil moisture and precipitation. Science, 305, 11381140, https://doi.org/10.1126/science.1100217.

_- , Y. Chang, H. Wang, and S. D. Schubert, 2016: Impacts of local soil moisture anomalies on the atmospheric circulation and on remote surface meteorological fields during boreal summers: A comprehensive analysis over North America. J. Climate, 29, 7345-7364, https://doi.org/10.1175/JCLI-D16-0192.1.
— - and Coauthors, 2017: Hydroclimate variability and predictability: A survey of recent research. Hydrol. Earth Syst. Sci., 21, 3777-3798, https://doi.org/10.5194/hess-21-3777-2017.

Lee, M.-H., S. Lee, H.-J. Song, and C.-H. Ho, 2017: The recent increase in the occurrence of a boreal summer teleconnection and its relationship with temperature extremes. J. Climate, 30, 7493-7504, https://doi.org/10.1175/JCLI-D-16-0094.1.

Mann, M. E., S. Rahmstorf, K. Kornhuber, B. A. Steinman, S. K. Miller, S. Petri, and D. Coumou, 2018: Projected changes in persistent extreme weather events: The role of quasi-resonant amplification. Sci. $A d v$., 4, eaat3272, https://doi.org/10.1126/ sciadv.aat3272.

Miralles, D. G., and Coauthors, 2018: Land-atmospheric feedbacks during droughts and heatwaves: State of the science and current challenges. Ann. N. Y. Acad. Sci., 1436, 19-35, https:// doi.org/10.1111/nyas.13912.

Petoukhov, V., S. Rahmstorf, S. Petri, and H. J. Schellnhuber, 2013: Quasiresonant amplification of planetary waves and recent Northern Hemisphere weather extremes. Proc. Natl. Acad. Sci. USA, 110, 5336-5341, https://doi.org/10.1073/pnas. 1222000110.

Schär, C., P. L. Vidale, D. Lüthi, C. Frei, C. Häberli, M. A. Liniger, and C. Appenzeller, 2004: The role of increasing temperature variability in European summer heatwaves. Nature, 427, 332336, https://doi.org/10.1038/nature02300.

Schubert, S. D., M. J. Suarez, P. J. Pegion, R. D. Koster, and J. T. Bacmeister, 2004: On the cause of the 1930s dust bowl. Science, 303, 1855-1859, https://doi.org/10.1126/science. 1095048.

Screen, J. A., and I. Simmonds, 2014: Amplified mid-latitude planetary wave favor particular regional weather extremes. Nat. Climate Change, 4, 704-709, https://doi.org/10.1038/ nclimate2271.

Seneviratne, S. I., and Coauthors, 2010: Investigating soil moisture-climate interactions in a changing climate: A review. Earth-Sci. Rev., 99, 125-161, https://doi.org/10.1016/ j.earscirev.2010.02.004.

Takaya, K., and H. Nakamura, 2001: A formulation of a phaseindependent wave-activity flux for stationary and migratory quasigeostrophic eddies on a zonally varying basic flow. J. Atmos. Sci., 58, 608-627, https://doi.org/10.1175/15200469(2001)058<0608:AFOAPI > 2.0.CO;2.

Tawfik, A. B., P. A. Dirmeyer, and J. A. Santanello Jr., 2015: The heated condensation framework. Part I: Description and Southern Great Plains case study. J. Hydrometeor., 16, 19291945, https://doi.org/10.1175/JHM-D-14-0117.1.

Teng, H., G. Branstator, H. Wang, G. A. Meehl, and W. M. Washington, 2013: Probability of U.S. heat waves affected by a subseasonal planetary wave pattern. Nat. Geosci., 6, 10561061, https://doi.org/10.1038/ngeo1988.

,,-- G. A. Meehl, and W. M. Washington, 2016: Projected intensification of subseasonal temperature variability and heat waves in the Great Plains. Geophys. Res. Lett., 43, 2165-2173, https://doi.org/10.1002/2015GL067574.

Trenberth, K. E., and J. T. Fasullo, 2012: Climate extremes and climate change: The Russian heat wave and other climate extremes of 2010. J. Geophys. Res., D17103, https://doi.org/ 10.1029/2012JD018020.

— G. Branstator, and P. A. Arkin, 1988: Origins of the 1988 North American drought. Science, 242, 1640-1645, https:// doi.org/10.1126/science.242.4886.1640.

, - - D. Karoly, A. Kumar, N.-C. Lau, and C. Ropelewski, 1998: Progress during TOGA in understanding and modeling 
global teleconnections associated with tropical sea surface temperature. J. Geophys. Res., 103, 14291-14324, https:// doi.org/10.1029/97JC01444.

Wang, H., S. Schubert, and R. Koster, 2017: North American drought and links to northern Eurasia: The role of stationary Rossby waves. Climate Extremes: Patterns and Mechanisms, Geophys. Monogr., Vol. 226, Amer. Geophys. Union, 195221, https://doi.org/10.1002/9781119068020.ch12.

,,--- , and Y. Chang, 2019: Phase-locking of the boreal summer atmospheric response to dry land surface anomalies in the Northern Hemisphere. J. Climate, 32, 1081-1099, https:// doi.org/10.1175/JCLI-D-18-0240.1.

Williams, I. N., and Coauthors, 2016: Land-atmosphere coupling and climate prediction over the U.S. Southern Great Plains. J. Geophys. Res. Atmos., 121, 12 125-12 144, https://doi.org/ 10.1002/2016JD025223

Yasui, S., and M. Watanabe, 2010: Forcing processes of the summertime circumglobal teleconnection pattern in a dry AGCM. J. Climate, 23, 2093-2114, https://doi.org/10.1175/ 2009JCLI3323.1. 
